The final publication is available at Elsevier via https://doi.org/10.1016/j.jconrel.2018.03.010 @ 2018. This manuscript version is made available under the CC-BY-NC-ND 4.0 license http://creativecommons.org/licenses/by-nc-nd/4.0/

\title{
Implant delivering hydroxychloroquine attenuates vaginal $T$ lymphocyte activation and inflammation
}

Yufei Chen ${ }^{1,2}$, Yannick L. Traore ${ }^{1}$, Sidi Yang ${ }^{1}$, Julie Lajoie ${ }^{3,7}$, Keith R. Fowke ${ }^{3,4,7}$, Daniel W. Rickey $^{5,6}$, and Emmanuel A. Ho ${ }^{1, *}$

${ }^{1}$ Laboratory for Drug Delivery and Biomaterials, School of Pharmacy, University of Waterloo;

${ }^{2}$ College of Pharmacy, University of Manitoba;

${ }^{3}$ Department of Medical Microbiology and Infectious Diseases, University of Manitoba

${ }^{4}$ Department of Community Health Sciences, University of Manitoba

${ }^{5}$ Department of Radiology, University of Manitoba

${ }^{6}$ Department of Physics \& Astronomy, University of Manitoba

${ }^{7}$ Department of Medical Microbiology, University of Nairobi

* Correspondence and proofs to be sent to:

Dr. Emmanuel A. Ho

Laboratory for Drug Delivery and Biomaterials

School of Pharmacy

University of Waterloo

10A Victoria St. S

Kitchener, Ontario N2G 1C5

Tel: 1-519-888-4567 x21372

Email: Emmanuel.ho@uwaterloo.ca 


\begin{abstract}
Evidence suggests that women who are naturally resistant to HIV infection exhibit low baseline immune activation at the female genital tract (FGT). This "immune quiescent" state is associated with lower expression of T-cell activation markers, reduced levels of gene transcription and proinflammatory cytokine or chemokine production involved in HIV infection while maintaining an intact immune response against pathogens. Therefore, if this unique immune quiescent state can be pharmacologically induced locally, it will provide an excellent women-oriented strategy against HIV infection To our knowledge, this is the first research article evaluating in vivo, an innovative trackable implant that can provide controlled delivery of hydroxychloroquine (HCQ) to successfully attenuate vaginal $\mathrm{T}$ lymphocyte activation and inflammation in a rabbit model as a potential strategy to induce an "immune quiescent" state within the FGT for the prevention of HIV infection. This biocompatible implant can deliver HCQ above therapeutic concentrations in a controlled manner, reduce submucosal immune cell recruitment, improve mucosal epithelium integrity, decrease protein and gene expression of T-cell activation markers, and attenuate the induction of key pro-inflammatory mediators. Our results suggest that microbicides designed to maintain a low level of immune activation at the FGT may offer a promising new strategy for reducing HIV infection.
\end{abstract}

\title{
Keywords
}

HIV/AIDS; hydroxychloroquine; antiviral; polymeric drug carrier; drug release; intravaginal ring 


\section{Introduction}

UNAIDS estimates that more than 36.7 million people lived with human immunodeficiency virus (HIV) in the world with approximately 1.8 million new HIV infections occurred globally in 2016 [1]. Ninety six percent of people that acquired HIV-1 infection live in developing countries and more than $70 \%$ of this population is located in Sub-Saharan Africa [2]. In Sub-Saharan Africa, women are twice as likely to acquire HIV compared to men [3]. Despite the fact that condoms are excellent for the prevention of HIV infection, the low availability of condoms and low frequency of condom use in this region hinder their protection against HIV infections and condom usage by some women is restricted due to socio-cultural factors [4]. Thus, efforts have been made to seek effective and affordable strategies to protect women against HIV-1 infection especially for those that live in developing countries.

The vaginal tract has been evaluated as a preferred administration route for a wide range of therapeutic agents such as those for contraception and the treatment of local vaginal infections. This is due to the presence of elastic rugae on the vaginal surface which greatly increases the surface area of the vaginal wall [5]. The abundant blood and lymphatic vessels in the wall of the vagina offer a path for therapeutic agents to be delivered to the local immune cells. The avoidance

of first-pass effect also enhances the bioavailability of therapeutic agents [6]. Medical devices that can provide controlled sustained drug delivery within the female genital tract such as intravaginal rings (IVR) have been shown to demonstrate various advantages over other conventional dosage forms (i.e. creams, gels, tablets, pessaries, foams, ointments, and douches) such as: (i) its ability to provide long-term controlled delivery of chemotherapeutics and macromolecules at the female genital tract (FGT) [7-9]; (ii) the ability to construct IVRs from various biocompatible elastomeric materials (polyurethane, pEVA, silicone, etc.) to offer tunable elution kinetics of therapeutic 
agents [10]; (iii) the ease of self-insertion and removal of IVRs resulting in high user adherence [11].

Most HIV transmissions occur at the genital mucosa. It was reported that the elevation of inflammatory mediators responsible for the recruitment of $\mathrm{T}$ cells and other HIV-target immune cells in the vaginal environment can facilitate HIV infection at the vaginal mucosa [12]. CD4+CCR5+ immune cells that are recruited to the exposure sites (i.e. activated T lymphocytes) are potential targets for HIV virus. Activated CD4+ or CD8+ T cells expressing CD69, HLA-DR, CD38, Ki67 were observed to be more susceptible to HIV infection and are the main cell types involved in HIV viral replication in comparison to their resting quiescent counterparts [13, 14]. Studies have also shown that nonoxynol-9 (N9), a spermicide that was initially reported as an effective agent for the disruption of infectious bacteria and envelope viruses including HIV [15], was later shown in clinical trials to increase HIV transmission due to an induction in vaginal inflammatory events within the FGT mainly through disruption of epithelial integrity and the induction of NF-kB activation dependent pro-inflammatory molecules [16-19]. Therefore, therapeutic agents able to maintain low frequencies of activated $\mathrm{T}$ cells and reduced level of inflammation in the female genital mucosa during HIV infection are of great interest as potential drug candidates against HIV infection. Hydroxychloroquine (HCQ), a hydroxyl analogue of chloroquine, is one of such promising candidates initially utilized for the treatment of malaria and rheumatoid arthritis [20]. HCQ has demonstrated direct anti-HIV activity by inhibiting gp120 glycosylation resulting in non-infectious HIV virions [21]. Since HCQ has been shown to possess immunomodulatory effects by decreasing the production of pro-inflammatory mediators [22] and inhibiting the expression of T-cell activation markers [23, 24], developing a strategy that can induce a T-cell immune quiescent state (maintaining a low basal expression level of pro- 
inflammatory mediators and reducing the frequency of activated T cells) locally at the FGT has the potential to effectively prevent or reduce HIV infection [13]. Previously, we successfully developed surfaced-modified matrix and segmented reservoir IVRs fabricated using hydrophilic polyether urethanes to provide sustained release of HCQ above therapeutic concentrations in vitro [25]. The developed IVRs had no significant impact on the integrity of vaginal epithelial cell monolayers and was non-cytotoxic towards vaginal and ectocervical epithelial cells or SupT1 T cells [26]. In the present study, we have further developed a non-invasive implant that can deliver HCQ in vivo within the FGT of a rabbit model and attenuate N9-induced vaginal mucosal inflammation and T-cell activation as a novel women-oriented HIV prophylaxis.

\section{Materials and Methods}

\subsection{Materials}

Hydrophilic aliphatic polyether urethane (PU) Tecophilic HP-60D-35 was purchased from Lubrizol Advanced Materials (Cleveland, OH, USA) with water swelling at 35\% (wt\%) of their dry mass and with shore hardness of 42D. HCQ ( $98 \%$ purity) was purchased from Thermo Fisher Scientific (Burlington, ON, Canada). Pharmaceutical grade hydroxypropyl methylcellulose (HPMC), METHOCEL K100M premium HPMC (assayed apparent viscosity: 97,579 mPa.s), was kindly offered by the Dow Chemical Company (New Milford, CT, USA). CellTiter 96® AQueous One Solution Cell Proliferation Assay (MTS) was purchased from Promega (Madison, WI, USA). E.Z.N.A.® RNA isolation kit was purchased from Omega Bio-Tek (Norcross, GA, USA). Rabbit TNF- $\alpha$, IFN- $\gamma$, IL-1- $\beta$, IL-6, IL-8, sandwich ELISA kits and associated buffers were purchased from R\&D Systems (Minneapolis, MN, USA). Rabbit macrophage inflammatory protein-3 $\alpha$ (MIP- 
3a) ELISA kit was purchased from Mybiosource (San Diego, CA, USA). Mouse anti-rabbit antiCD3 was purchased from BD Biosciences (Mississauga, ON, Canada). RPMI-1640 cell culture medium, fetal bovine serum (FBS), penicillin-streptomycin, phosphate-buffered saline (PBS), HEPES, EDTA were purchased from Thermo Fisher Scientific (Burlington, ON, Canada). Collagenase was obtained from Sigma-Aldrich (Mississauga, ON, Canada). Percoll and FicollPaque $^{\text {TM }}$ PLUS solutions were purchased from GE Healthcare (Chicago, IL, USA). All other solvents and reagents were obtained as HPLC grade unless noted.

\subsection{Rabbit HCQ implant design and fabrication}

Each rabbit implant was comprised of a flexible PU drug-permeable portion, end-capped with non-water permeable solid PU and embedded with two flexible arms. The drug-permeable portion and flexible arms of the implant was manufactured via hot-injection molding and hot-melt extrusion, respectively. Briefly, the hydrophilic polyether urethane HP-60D-35 was dried overnight in an oven set at $80^{\circ} \mathrm{C}$. The drug-permeable portion of the implant was then fabricated by hot-melt injection molding at $160^{\circ} \mathrm{C}$ using a benchtop hot injection molder (Medium Machinery, LLC, Woodbridge, VA, USA) and a custom designed mold as previously described [25]. The curved drug-permeable portion had a cross-sectional diameter (XD) of $5 \mathrm{~mm}$ and a wall thickness of $0.75 \mathrm{~mm}$. The XD and wall thickness of each fabricated segment was measured with a digital caliper. The same HP-60D-35 was hot-melt extruded at the same temperature using a Thermo Scientific ${ }^{\mathrm{TM}}$ HAAKE $^{\mathrm{TM}}$ MiniLab II Micro Compounder coupled with a rod die (1.5 $\mathrm{mm}$ in outer diameter). The prototype solid portion of the implant was designed using Geomagic ${ }^{\circledR}$ Design $\mathrm{X}$ (3D Systems; Rock Hill, South Carolina, USA) and 3D printed in ABS using a commercially available fused deposition modeling printer (Robox, CEL, UK). A silicon mold of the print was

made using Mold Max ${ }^{\circledR} 25$ (Smooth-on, Inc., Macungie, PA, USA) and the final product was 
solvent-casted using Smooth-Cast ${ }^{\circledR}$ 300, a urethane-based water-impermeable material. Each end of the flexible portion of the implant was sealed with Smooth-Cast ${ }^{\circledR} 300$ and the same material was applied to the tips of the arms creating a smooth surface. During the study, the lumens of the implants were either filled with aqueous-buffered HCQ in PBS (pH 7.4) or HCQ/K100M semisolid (at different w/w ratio). The $\mathrm{HCQ} / \mathrm{K} 100 \mathrm{M}$ semi-solid was prepared using a two-syringe mixing method described previously [26]. To monitor the implant presence within the rabbit vaginal cavity post-insertion, each implant lumen was embedded with an ID-100A radio-frequency identification (RFID) Nano Transponder (1.25 $\mathrm{mm}$ in diameter, $7 \mathrm{~mm}$ in length, Trovan $\left.{ }^{\circledR}\right)$, enabling real-time identification throughout the study with minimal impact on drug loading capacity.

\subsection{In vivo evaluation}

The animal protocol for in vivo experiments was approved by the Animal Care Committee at the University of Manitoba. Sexually mature female NZW rabbits (3.5-4.5 kg in weight, 5-8 month old) were purchased from Charles River Laboratories (Saint-Constant, QC, Canada). Upon arrival, rabbits were single-housed in standard stainless-steel cages one week prior to initiation of studies. The animals were divided into five groups: naïve (without implant), placebo (with implant containing no HCQ), HCQ only (with implant containing aqueous-buffered HCQ), N9 only (challenged with N9 for $24 \mathrm{hr}$ without implant), and N9+HCQ (challenged with N9 for $24 \mathrm{hr}$ with implant containing HCQ). N9 challenge was performed by introducing $1 \mathrm{~mL}$ of Conceptrol ${ }^{\circledR}$ gel (containing 4\% N9) into the rabbit vaginal cavity on day 5. A slightly lubricated 1-mL syringe

containing $1 \mathrm{~mL}$ of Conceptrol ${ }^{\circledR}$ gel was gently inserted approximately $10 \mathrm{~cm}$ from the introitus with the gel being dispensed slowly into the vaginal canal. All groups were terminated on day 6 for blood and tissue collection as well as implant retrieval. Blood $(\sim 20 \mathrm{~mL})$ was collected via 
cardiac puncture by inserting the needle immediately caudal to the zyphoid process and penetrating the heart. Following anesthetization with 5\% isoflurane in the presence of oxygen, animals were euthanized by injecting pentobarbital sodium (Euthanyl) at a dose of $2 \mathrm{~mL} / 4.5 \mathrm{~kg}$ of body weight by cardiac puncture. We divided the collected rabbit vaginal tract into three sections for analysis: the $8-10 \mathrm{~cm}$ lower urovagina (UV), the 5-6 $\mathrm{cm}$ middle distal cervicovagina (DC) which was directly in contact with the implant, and the $4-5 \mathrm{~cm}$ upper proximal cervicovagina (PC). All samples were stored in $-80^{\circ} \mathrm{C}$ until further analysis unless indicated otherwise.

Medical-grade NSF-61 ester-based PU tubing $(7.95 \mathrm{~mm}$ in cross-sectional diameter, 0.78 mm in wall thickness, 85A shore hardness, Component Supply Company, Sparta, TN, USA) was utilized for the implantation procedure. Animals were anesthetized with 5\% isoflurane in the presence of oxygen. Implants were lubricated with the water-soluble Lubricating Jelly (HealthCare Plus) and gently inserted into one end of the NSF-61 PU tubing. After applying a thin layer of lubricant, the PU tubing containing the implant was slowly inserted $8-10 \mathrm{~cm}$ into the anterior vagina. Deployment of the implant was facilitated by insertion of a sterile metal rod into the other end of the PU tubing and gently releasing the implant into the upper portion of the rabbit vagina past the urethovaginal sphincter. Thereafter, the PU tubing and metal rod were slowly removed. Rabbits with the implants were returned to their original cage. The entire procedure was performed within 10 minutes. Following the implantation, the animals were closely monitored during anesthetic recovery for physiological disturbances including cardiovascular/respiratory depression, hypothermia, and any bleeding or discharge from the vaginal tract. Animals were monitored daily for the presence of the implant by gently placing the RFID reader beneath the pelvic area of each implanted animal. Measured body weight and any negative clinical observations were recorded daily. 
To collect CVL samples from rabbits at each time interval (day $0,1,2,3,5$, and 6), the rabbits were anesthetized using an isoflurane/oxygen vaporizer and placed in supine position keeping their back as straight as possible. $1 \mathrm{~mL}$ of sterile PBS (pH 7.4) was introduced carefully to flush the rabbit vaginal tract and 4-5 pieces of HydraFlock ${ }^{\circledR}$ Flocked Swabs (Puritan Medical Products, Guilford, ME, USA) were gently inserted $8 \mathrm{~cm}$ into the vaginal tract to absorb the lavage. CVL was centrifuged at $12,000 \mathrm{x}$ g for $3 \mathrm{~min}$ to remove cell debris and the final volume of CVL remaining was approx. 500-600 $\mu \mathrm{L}$. Blood samples (1-1.5 mL) were collected via ear vein into BD Vacutainer ${ }^{\circledR}$ blood collection tubes. Both CVL and blood samples were stored in $-80^{\circ} \mathrm{C}$ until further analysis.

\subsection{X-ray imaging of HCQ implant in rabbit}

The rabbits for X-ray imaging were anesthetized via intramuscular injection of ketamine and xylazine at a dose of $35 \mathrm{mg} / \mathrm{kg}$ and $5 \mathrm{mg} / \mathrm{kg}$, respectively. Images were acquired using a laboratory X-ray system comprised of a flat-panel detector (Varian Medical Systems, Salt Lake City, UT, USA), X-ray tube (Varian Medical Systems) and generator (Sedecal, Buffalo Grove, IL, USA). Images were acquired with tube potentials of $40 \mathrm{kV}$ to $50 \mathrm{kV}$ and mAs settings ranging from 1 to 8.

\subsection{Reversed-phase HPLC (RP-HPLC) quantitation of HCQ in rabbit CVL, tissue and in implants}

HPLC analysis was carried out using a Waters Nova-Pak ${ }^{\circledR} \mathrm{C} 18$ column $(4 \mu \mathrm{m}, 3.9$ x $150 \mathrm{~mm})$ under isocratic conditions equipped on a Shimadzu LC-2010A HPLC system. The mobile phase consisted of methanol, acetonitrile, and $58 \mathrm{mM}$ sodium phosphate dibasic buffer (4:22:74, v/v) containing $15 \mathrm{mM}$ heptanesulphonic acid and adjusted to $\mathrm{pH} 3.1$ with concentrated phosphoric 
acid. The mobile phase was delivered at a flow rate of $1.0 \mathrm{~mL} / \mathrm{min}$. Column temperature was maintained at $25^{\circ} \mathrm{C}$. Data was recorded at $343 \mathrm{~nm}$. The retention time of HCQ and CQ in CVL samples were approximately $13.3 \mathrm{~min}$ and $17.3 \mathrm{~min}$ while the retention time of HCQ and CQ in tissue samples were approximately $10.8 \mathrm{~min}$ and $13.9 \mathrm{~min}$, respectively. A linear calibration curve of HCQ was obtained in the range of $49-1250 \mathrm{ng} / \mathrm{mL}\left(\mathrm{R}^{2}>0.999\right)$ for CVL samples and 150-2000 $\mathrm{ng} / \mathrm{mL}\left(\mathrm{R}^{2}>0.999\right)$ for tissue samples. The limit of quantification for HCQ was $24 \mathrm{ng} / \mathrm{mL}$ in $\mathrm{CVL}$ samples and $78 \mathrm{ng} / \mathrm{mL}$ in tissue or blood samples.

Analysis of HCQ in CVL was performed using a reversed-phase HPLC (RP-HPLC) method that was described previously with slight modifications [27]. HCQ was first extracted from 100 $\mu \mathrm{L}$ of rabbit CVL samples by adding $300 \mu \mathrm{L}$ of acetonitrile and $1 \mu \mathrm{L}$ of $5 \mathrm{mg} / \mathrm{mL}$ chloroquine (CQ, internal standard) and vortexed for 1 min. Protein content was separated by centrifugation at $20,000 \mathrm{x} \mathrm{g}$ at $4^{\circ} \mathrm{C}$ for $20 \mathrm{~min}$. After transferring the supernatant into a new tube, the contents were evaporated in a Savant ${ }^{\mathrm{TM}}$ SpeedVac ${ }^{\mathrm{TM}}$ Vacuum Concentrator (Thermo Fisher Scientific) at $45^{\circ} \mathrm{C}$ with a vacuum pressure set at 5.1 torr for $1.5 \mathrm{hr} .100 \mu \mathrm{L}$ of HCQ mobile phase was used to reconstitute the content in the vial and $80 \mu \mathrm{L}$ was injected for HPLC analysis. HCQ in rabbit vaginal tissue or blood was first extracted and then analyzed by RP-HPLC using a modified extraction technique as previously reported [28]. Briefly, $500 \pm 50 \mathrm{mg}$ of rabbit vaginal tissue (UV, DC, and PC portions) were weighed in a $1.5 \mathrm{~mL}$ microcentrifuge tube with the addition of $400 \mu \mathrm{L}$ of $3 \mathrm{mg} / \mathrm{mL}$ collagenase in water. $100 \mu \mathrm{L}$ of internal standard CQ at $50 \mu \mathrm{g} / \mathrm{mL}$ in water was spiked into each sample. Samples were shaken at $37^{\circ} \mathrm{C}$ overnight at $160 \mathrm{rpm}$ on a benchtop orbital shaker to digest the tissue and release drug content. The following day, samples were homogenized and transferred into $50-\mathrm{mL}$ tubes, followed by the addition of $1 \mathrm{~mL}$ of PBS (pH 2.5), $2 \mathrm{~mL}$ of $0.4 \mathrm{~N}$ $\mathrm{NaOH}$, and $8 \mathrm{~mL}$ of chloroform. The samples were then vortexed and centrifuged to remove the 
aqueous phase. $1 \mathrm{~mL}$ of PBS (pH 5) was added into the organic phase and the mixture was vortexed for 2 min. After centrifugation, the organic phase containing HCQ was transferred to a clean glass tube for evaporation. $500 \mu \mathrm{L}$ of mobile phase was added to reconstitute the content in the tube and $200 \mu \mathrm{L}$ of filtered sample was injected into the HPLC column. HCQ in blood was extracted following similar procedures but without the collagenase treatment. To quantify residual HCQ remaining in each implant after the animal studies, the solution within the lumen of each retrieved implant containing residual HCQ was first aspirated out by a 1-mL syringe followed by three washes of the lumen with $100 \mu \mathrm{L}$ of distilled water. The wash solution was collected, combined and lyophilized using a bench-top freeze dry system (LABCONCO ${ }^{\circledR}$ FreeZone). The sample was then reconstituted in $100 \mu \mathrm{L}$ of mobile phase, filtered, and $40 \mu \mathrm{L}$ of the sample was injected into the HPLC system. The determined amount of leftover HCQ was compared to the initial drug loading of each implant.

The HCQ extraction efficiency from each biological matrix were determined by spiking both HCQ standard solutions at various known concentrations along with the internal standard, CQ, following the same procedure described above for quantitating the HCQ levels in each biological matrix respectively (Supplementary Table S1). At least three HCQ spiking controls (each run in triplicates) covering the low, medium, and high concentration ranges of HCQ were run simultaneously with the samples. The average extraction efficiency, as expressed in percentage (obtained via dividing the assayed concentrations by the spiked concentrations), was then used for HCQ concentration calculations in each sample.

\subsection{Isolation of lymphocytes from rabbit vaginal tract mucosa}

After the animals were euthanized, lymphocytes from rabbit vaginal mucosa were isolated similarly as described by Jiang et al [29]. Briefly, for each rabbit, the UV, DC, and PC portions of 
the vaginal tract were pooled, cut into fine pieces and digested in RPMI-1640 medium supplemented with $450 \mathrm{U} / \mathrm{mL}$ of collagenase, 1\% penicillin/streptomycin, 1M HEPES and 10\% heat-inactivated fetal bovine serum (HI-FBS) at $37^{\circ} \mathrm{C}$ for $1 \mathrm{hr}$ on an orbital incubator. The cell suspension was collected through a $100 \mu \mathrm{m}$ cell strainer and the vaginal mucosal immune cells were isolated by Percoll (Sigma-Aldrich) density gradient at $900 \mathrm{x}$ g for $20 \mathrm{~min}$. The interface layer containing the lymphocytes were carefully collected and washed with RPMI-1640 containing $10 \%$ HI-FBS for T-cell isolation and flow cytometry analysis.

Vaginal mucosal T cells were isolated using Dynabeads ${ }^{\circledR}$ FlowComp ${ }^{\mathrm{TM}}$ Flexi Kit (Thermo Fisher Scientific) following the manufacturer's instruction. Mouse anti-rabbit T lymphocyte antibody (clone KEN-5, Bio-Rad, Hercules, USA) was biotinylated using the DSB-X Biotin Protein Labeling Kit according to the manufacturer's instructions. Briefly, around $8 \times 10^{6}$ of isolated vaginal mucosal immune cells from the previous step was labeled with DSB-X biotinylated antibody $(300 \mu \mathrm{g} / \mathrm{mL})$ for $30 \mathrm{~min}$ on ice. Antibody-coated cells were incubated with washed Dynabeads ${ }^{\circledR}$ to positively select $\mathrm{T}$ cells from other cell types at $4^{\circ} \mathrm{C}$ for $15 \mathrm{~min}$ with gentle agitation. The samples were then placed onto a magnetic tube rack and the separated $\mathrm{T}$ cells were washed and released from the Dynabeads ${ }^{\circledR}$ and collected by centrifugation.

\subsection{Flow cytometry analysis}

Isolated vaginal mucosa immune cells $\left(6 \times 10^{6}\right)$ were washed with $2 \%$ HI-FBS in PBS. After permeabilization with $1 \%$ saponin and fixed with $2 \%$ paraformaldehyde, cells were stained at $4{ }^{\circ} \mathrm{C}$ for 30 min with APC-CD3ع, DyLight 405-CD4, DyLight 488-CD8 $\alpha$ (Novus Biologicals, Oakville, ON, Canada), and PE-RLA-DR (Cedarlane Labs, Burlington, ON, Canada). Data was acquired on 
a FACS Canto II flow cytometer (BD Biosciences, San Jose, CA, USA) and analyzed using FlowJo v10.0.7r2 (FlowJo, LLC, Ashland, OR, USA).

\subsection{Quantitative RT-PCR}

Using the vaginal mucosal T cells purified earlier with Dynabeads ${ }^{\circledR}$, total RNA was extracted using the PureLink ${ }^{\circledR}$ RNA Mini Kit (Thermo Fisher Scientific) following manufacturer's instructions. The concentration of extracted RNA was determined using a NanoDrop ${ }^{\text {TM }} 2000$ spectrophotometer and cDNA was generated using the SuperScript ${ }^{\mathrm{TM}}$ VILO $^{\mathrm{TM}}$ cDNA Synthesis Kit (Invitrogen, USA). Real-time RT-PCR was performed using PerfeCTa ${ }^{\circledR}$ SYBR $^{\circledR}$ Green SuperMix (Quanta Biosciences, Beverly, MA, USA) with the Applied Biosystems ${ }^{\circledR}$ QuantStudio ${ }^{\text {TM }} 6$ Flex Real-Time PCR System using $2 \mu \mathrm{L}$ of a 1:4 cDNA dilution (50 ng of total cDNA) in DNase-free RNase-free water in a final volume of $20 \mu \mathrm{L}$ with $250 \mathrm{nM}$ final primer concentrations. Rabbit GAPDH was used as an endogenous control. GAPDH $\mathrm{RT}^{2}$ qPCR Primer Assay was purchased from QIAGEN (Toronto, ON, Canada). The following primers were purchased from Dharmacon (ON, Canada):

CCR5 forward: 5'- GTCAGAGCCCTGCCAAAAAAT-3',

CCR5 reverse: 5'-CACGAAGCCGAAAATGAACAC-3';

CD69 forward: 5'- TGGTCCAGCGTAAAGCAGTAAG-3',

CD69 reverse: 5'- CGAAACAGCGTCTGACTCCTT-3'.

\subsection{Pro-inflammatory cytokine and chemokine assays}

At each time interval, the production of IL-1 $\beta$, IL-6, IL-8, TNF- $\alpha$, MIP-3 $\alpha$ in rabbit CVL samples were determined by sandwich ELISA kits purchased either from R\&D Systems (Minneapolis, MN, USA, for IL-6, IL-8, and TNF- $\alpha$ ), Biomatik (Cambridge, ON, Canada, for IL-1 $\beta$ ), or Mybiosource 
(San Diego, CA, USA, for MIP-3 $\alpha$ ) using $100 \mu \mathrm{L}$ of un-diluted CVL samples. To quantitate the tissue-associated cytokine and chemokine levels, $20 \pm 5 \mathrm{mg}$ of UV, DC, and PC portions of vaginal tissue collected from different groups were homogenized on ice in PBS containing a protease inhibitor cocktail (Sigma-Aldrich, ON, Canada) and centrifuged at $20,000 \mathrm{x}$ g at $4^{\circ} \mathrm{C}$ for $20 \mathrm{~min}$. The total protein concentration in the supernatant was assayed using BCA assay (Thermo Fisher Scientific). Diluted samples containing $100 \mu \mathrm{g}$ of total protein were used in sandwich ELISA for the quantitation.

\subsection{Histological morphology analysis}

Upon euthanization of the animals at the end of the study, different portions of the vaginal tract (UV, DC, and PC) were collected for histological morphology analysis. Fresh tissues were fixed in $10 \%$ buffered formalin overnight at $4^{\circ} \mathrm{C}$ in a conical tube and processed on a Shandon Citadel ${ }^{\mathrm{TM}}$ 1000 Tissue Processor (Thermo Fisher Scientific) with subsequent ethanol/xylene incubation. Thereafter, processed tissues were embedded in paraffin using a Microm EC350 Paraffin Embedding Center (Thermo Fisher Scientific). Embedded tissues were sectioned into 5- $\mu$ m-thick slices using a HM 355S Automatic Microtome (Thermo Fisher Scientific) and prepared on glass slides. The slides were then stained with hematoxylin and eosin (H\&E). The stained slides were assessed, unblended, and images were acquired on an Eclipse Ti-S inverted microscope equipped with a DS-U3 DS Camera Control Unit powered by a TI-PS30W power supply (Nikon Instruments Inc., NY, USA). No blinding was done. For all three sections of the vaginal tract in each group, at least three images were obtained for each rabbit.

\subsection{Statistical analysis}


All data sets were analyzed using GraphPad Prism 6.0 (GraphPad software, San Diego, CA, USA) and Microsoft Excel (Microsoft, Redmond, WA, USA). For group comparison, an analysis of variance (ANOVA) with Bonferroni as post-test was performed using adjusted p-values. Statistical significance was defined as a $\mathrm{p}<0.05$. In figures (if not defined additionally), the significant values are depicted as follows: ${ }^{*} \mathrm{p}<0.05 ; * * \mathrm{p}<0.01 ; * * \mathrm{p}<0.001$.

\section{Results}

\subsection{Design and manufacture of a PU HCQ implant for rabbit}

Previously, in vivo evaluations of implantable vaginal dosage forms were invasive and required suturing of the test dosage forms within the vaginal cavities of animals [30] and monitoring of the implant relied on invasive procedures (i.e. endoscopy) [31]. However, these procedures need to be avoided in the current study, as they are likely to induce inflammation within the rabbit genital tract. As a result, we developed a vaginal implant that can non-invasively remain within the FGT for prolonged periods of time while providing controlled sustained release of HCQ.

We prepared a T-shaped implantable dosage form comprised of four elements: (i) a curved hydrophilic HCQ-permeable portion $(5 \mathrm{~mm}$ in cross-sectional diameter with a wall thickness of $0.75 \mathrm{~mm}$ ) fabricated through hot-injection molding with medical-grade PU, HP-60D-35 (Fig. 1a);

(ii) two flexible $1.5 \mathrm{~mm}$-long arms (diameter of $1.5 \mathrm{~mm}$ ) that were manufactured via hot-melt extrusion of the same PU (Fig. 1a); (iii) the solid non-HCQ-permeable portions made of solventcasted PU (Smooth-Cast ${ }^{\circledR}$ 300, Smooth-On, Inc.) to seal the implant and immobilize the arms (Fig. 1b); (iv) a radio frequency identification (RFID) Nano Transponder (1.25 $\mathrm{mm}$ in diameter, $7 \mathrm{~mm}$ 
a

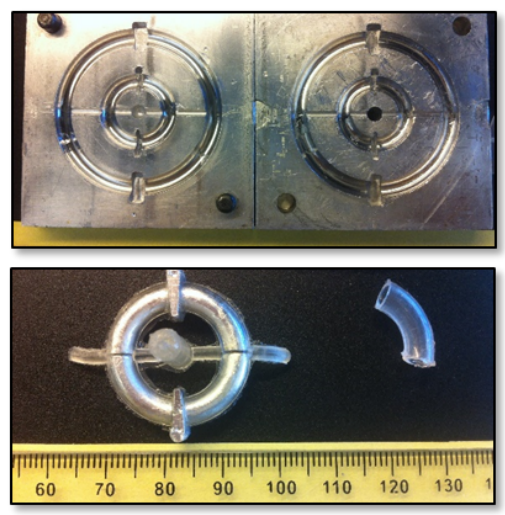

b

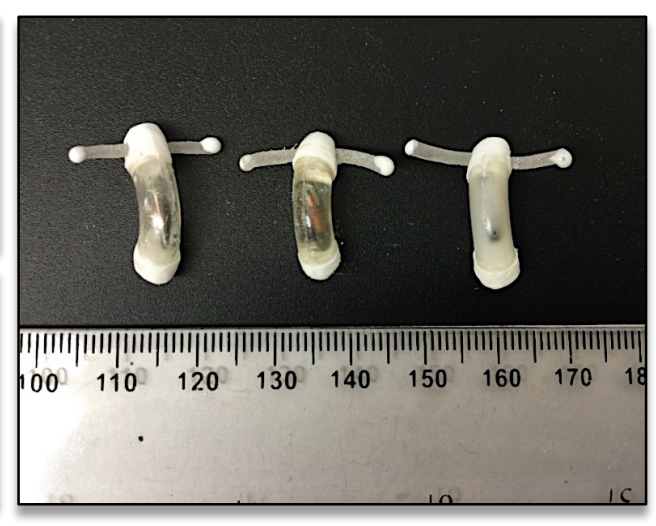

C

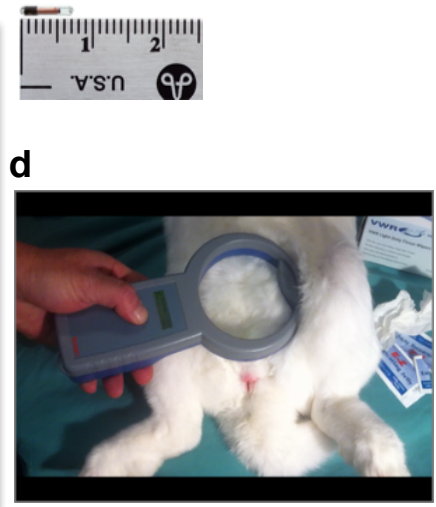

Fig. 1. Design and fabrication of rabbit PU HCQ implant (a) Custom designed mold for hot injection molding and the resulting PU segment for fabricating the hydrophilic drug-permeable portion of the rabbit implant. (b) Representative fabricated T-shaped placebo implant (left), implant containing aqueousbuffered HCQ (middle), and implant loaded with HPMC semi-solid containing HCQ with two flexible arms (right). The lumens of the implant were embedded with an RFID transponder for real-time tracking. Nondrug-permeable PU (solid white color) was used to cap both ends of the implant and applied to the tips of the arms to provide a smooth surface. (c) The dimension of a Trovan ${ }^{\circledR}$ ID-100A RFID Nano Transponder. (d) Tracking the RFID-embedded implant within the rabbit using a RFID reader by placing the reader over the pelvic area of the animal. HCQ, hydroxychloroquine; PU, polyurethane; HPMC, hydroxypropyl methylcellulose; RFID, radio-frequency identification. 
in length, Trovan ${ }^{\circledR}$; ID-100A) for tracking the implant (Fig. 1c). Previously, we have shown that the $35 \%$ water-swellable hydrophilic HP-60D-35 was capable of providing sustained release of HCQ in vitro within therapeutic concentrations required for inhibiting T-cell activation from a reservoir-type IVR [25]. Furthermore, neither the selected material nor the HCQ released from this device affected the cellular viability of Lactobacillus crispatus and jensenii (microflora commonly found in healthy human FGT), human SupT1 T cells and human vaginal or ectocervical epithelial cells [26]. Results also showed that the material we selected for fabricating our implant was noncytotoxic and did not induce the expression of key pro-inflammatory mediators IL-1 $\beta$, IL-6, or IL8 in rabbit CVL (Fig. S2). Previous studies have shown that implants with a cross-sectional diameter of approximately $8-10 \mathrm{~mm}$ can be well tolerated by female NZW rabbits when inserted into the FGT [32]. We carefully trimmed the HCQ implant under a sterile environment to approximately $8 \mathrm{~mm}$ in diameter (measured after folding both T-shaped arms towards the implant body) to ensure the implant can smoothly traverse through a flexible medical-grade PU tubing (Fig. S1) and be deployed within the rabbit vaginal lumen. RFID tags have been an inexpensive solution readily available for automated long-term tracking of animals [33]. Since NZW rabbits are sensitive to environmental stress and their daily movement may result in unanticipated implant expulsion, we incorporated RFID micro transponders in each implant (Fig. 1b, c) for rapid noninvasive monitoring within the rabbit FGT (Fig. 1d).

\subsection{Non-invasive implantation and vaginal residence evaluation}

It should be noted that in female NZW rabbits the urethral orifice opens into the vagina about $8-10 \mathrm{~cm}$ proximal from the introitus, resulting in an anatomical structure called urethrovaginal sphincter to be present mid-way within the FGT [34]. Therefore, the implant must 
a

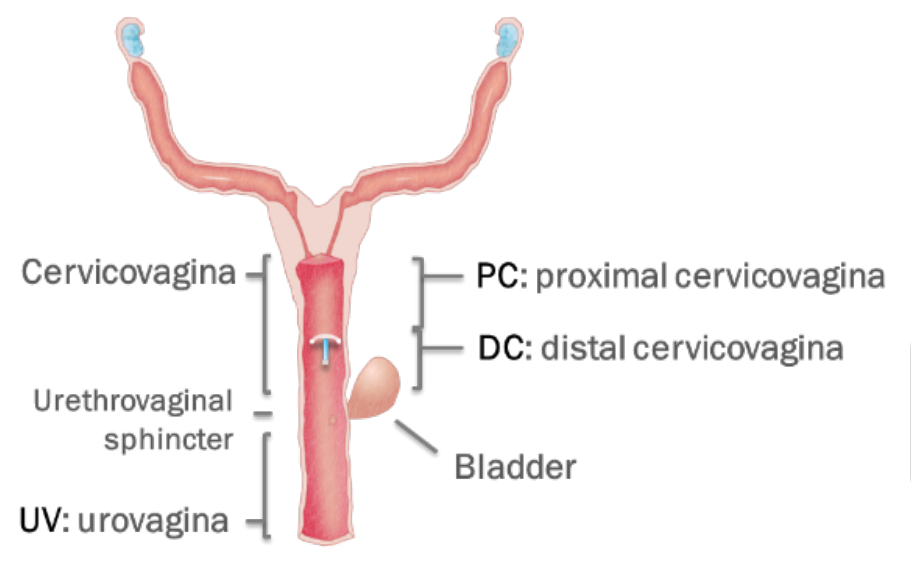

b

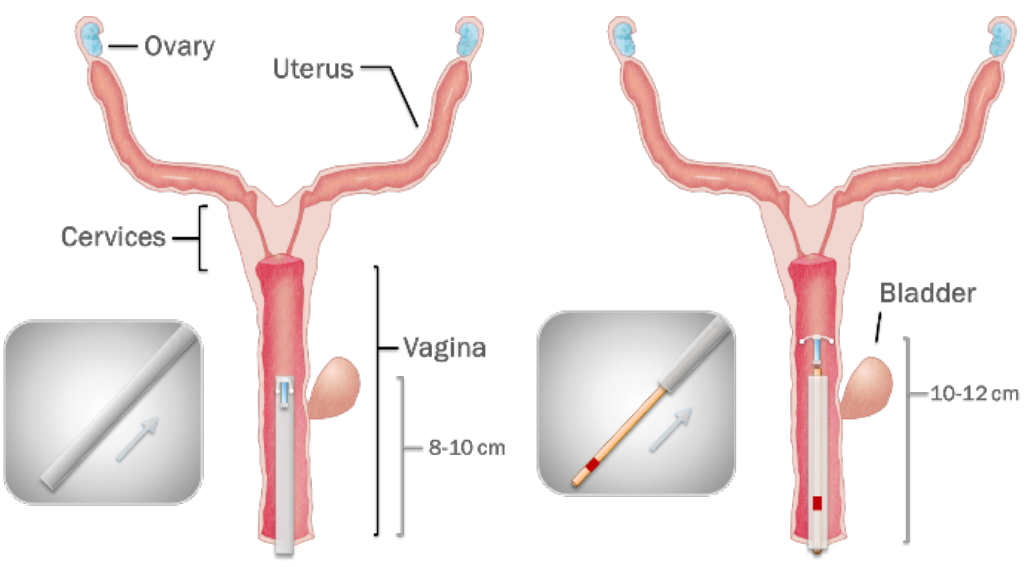

C

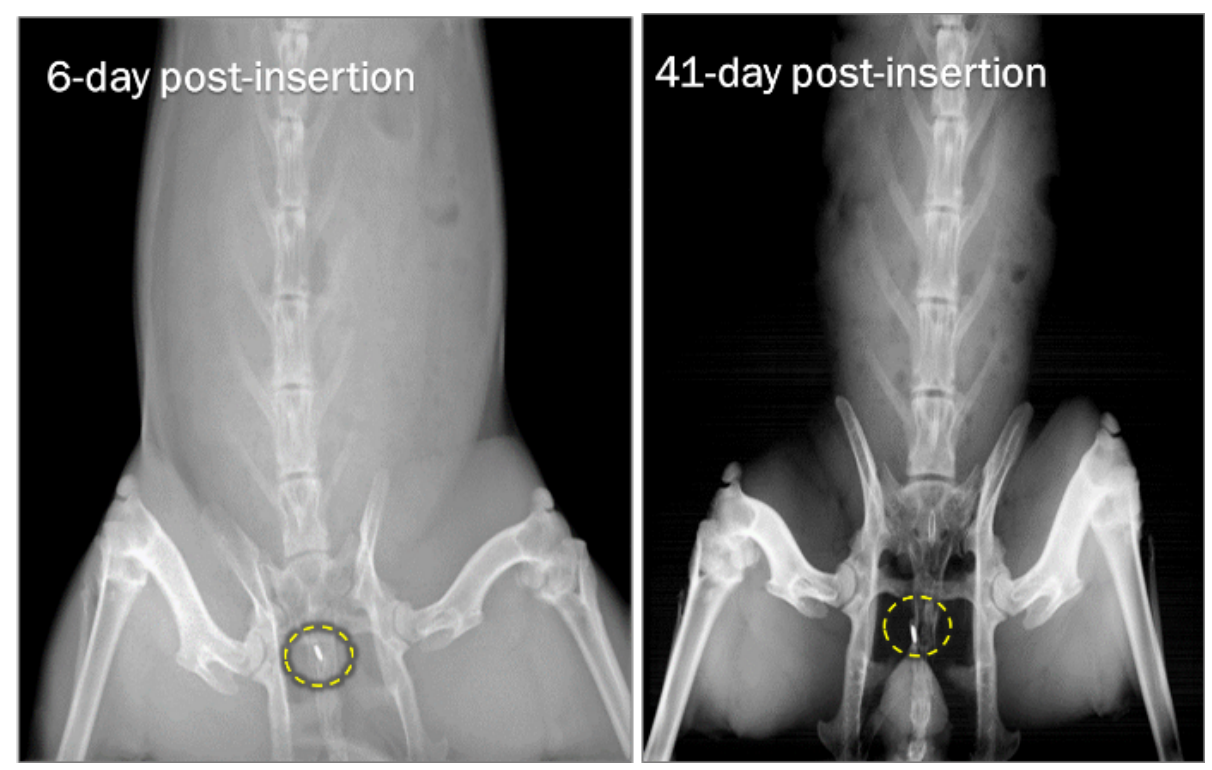

Fig. 2. Non-invasive implantation of the HCQ implant and x-ray evaluation of its long-term vaginal residence in rabbits. (a) Schematic illustration of the rabbit genital tract and site implantation. The site within the female genital tract in direct contact with the implant was defined as the distal portion of the cervicovagina (DC). The upper segment was defined as the proximal portion of the cervicovagina (PC). (b) Schematic illustration of the implantation procedure. During the implantation, the sterile medical grade PU tubing ( $\mathrm{OD}=8 \mathrm{~mm}$, lubricated with the implant pre-inserted) was gently inserted $8-10 \mathrm{~cm}$ into the rabbit vagina (Left image). The implant was then released by gently pushing a lubricated sterile copper rod $(\mathrm{OD}=3.2 \mathrm{~mm})$ forward, leaving the implant at a depth of $10-12 \mathrm{~cm}$ from the vaginal vulve (Right image). (c) X-ray imaging was used to confirm retention of the implant (circled) within the rabbit female genital tract for over 40 days. 
be placed past the urethrovaginal sphincter to prevent wash-out of drug content by urine (Fig. 2a). We characterized our HCQ implant in vivo for its ability to (i) be deployed past the urethrovaginal sphincter, (ii) be implanted rapidly and non-invasively, (iii) remain safely within the FGT for prolonged periods of time without causing obstruction or mucosal injury.

The ability to be implanted easily without expulsion out of the FGT is related to the selected material, geometric, and mechanical factors. The thermoplastic PU utilized in the current study possessed appropriate elastomeric properties with a shore hardness of 42D, offering adequate flexibility to balance the requirements between the tolerance for slight compression of the implant body during implantation and the hardness needed for safely remaining within the FGT. The implantation (Fig. 2b) was non-invasively conducted using a lightly lubricated flexible medicalgrade PU tubing, followed by deployment of the implant via a sterilized metal rod. The implant was precisely placed upstream of the urethrovaginal sphincter as evidently revealed after dissection (Fig. S3). Of more than 32 implants administrated to different rabbits, all implants deployed properly within the first $5 \mathrm{~min}$. The flexible arms of the implant were able to undergo a high degree of compression to smoothly fit into the PU tubing without damage. Upon deployment, the arms re-opened to supply sufficient force to retain the implant within the FGT. The rabbits were monitored daily throughout the study period and no adverse reactions were observed. Specifically, observations were made to look for abnormal increases in abdomen size, changes to normal daily behavior, swelling of the vaginal introitus or the presence of blood during the implantation procedure or in the collected CVL samples of the implanted animals. Furthermore, the volume of CVL collected was recorded to ensure there was no obstruction of vaginal fluid flow or signs of vaginal irritation. Vaginal residence of the implants was evaluated by X-ray imaging of the embedded micro transponder taken at various time points post-implantation (Fig. 2c), 
revealing that the implant can remain within the FGT for $>40$ days. There was also no significant weight loss or abnormal vaginal discharge observed in the implanted rabbits during the study (Fig. S3). Compared to the naive group, rabbits treated with HCQ-containing implants for 30 days did not elicit any obvious signs of lymphocyte infiltration or disruption of epithelium integrity at the site of direct implant contact (Fig. S4). We assessed the production of the pro-inflammatory indicators IL-1 $\beta$ and IL-8 [18] in cervicovaginal fluid (CVL) of the animals that received the implants (Fig. S5). No statistical differences in the levels of these markers were observed among naïve, placebo, and the group that were treated with HCQ-containing implants within the 30 days study period. In summary, we demonstrated the potential of this innovative trackable implant device to offer prolonged residence within the FGT of rabbits without eliciting unwanted local inflammation.

\subsection{In vivo HCQ delivery within rabbit genital tract}

Implants containing different concentrations of HCQ were inserted into the rabbit vaginal tract for 6 days and $1 \mathrm{~mL}$ of $\mathrm{N} 9$ gel (4\%) was introduced into the vaginal lumen on day 5 (Fig. 3a). The rabbit CVL samples were collected on days 1, 3, 5, 6 and HCQ concentrations were analyzed by reversed-phase high-performance liquid chromatography. Given the fact that slower in vivo drug elution rates from IVR-based microbicides have been reported in other studies $[32,35]$ and the high water solubility of HCQ $(>2 \mathrm{~g} / \mathrm{mL})$, we initially assessed different dosage forms containing 10 times higher HCQ loading (40 mg) with higher ratios of HCQ to the rate-controlling excipient HPMC (w/w, 50:1 and 5:1) than previously tested in vitro [25] and compared them with implants loaded with aqueous-buffered HCQ (Fig. 3b). Results showed that the presence of HPMC decreased the rate of HCQ release into CVL, resulting in levels insufficient for therapeutic effects

(Fig. 3b, d). In contrast, the implant containing aqueous-buffered HCQ (40 mg loading) reached 

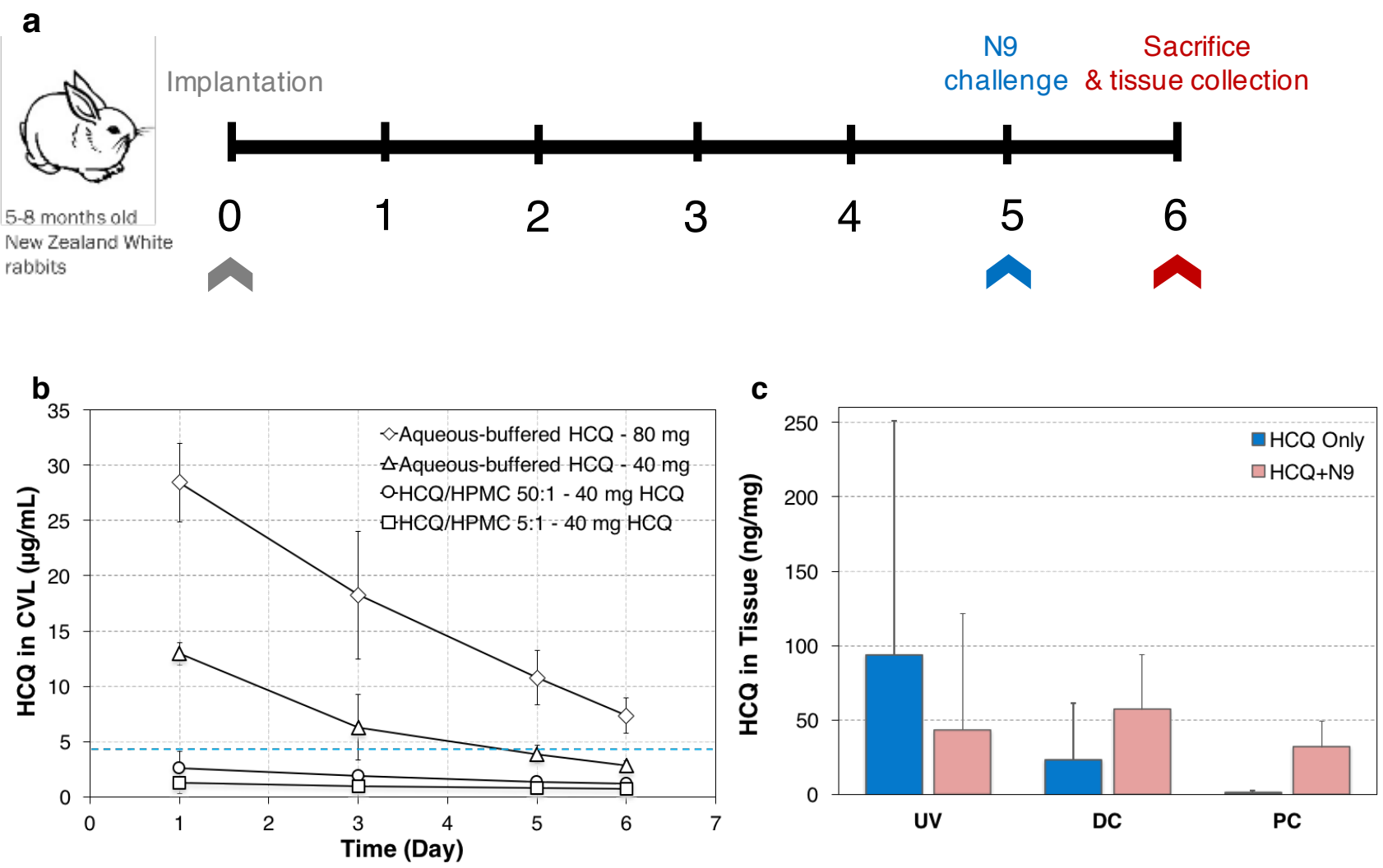

\begin{tabular}{|c|c|c|c|}
\hline f & $\begin{array}{c}\text { Total drug } \\
\text { incorporated } \\
(\mathrm{mg})\end{array}$ & $\begin{array}{c}\mathrm{HCQ} \text { delivery } \\
\text { rate } \\
(\mu \mathrm{g} / \mathrm{mL} / \text { day })\end{array}$ & $\begin{array}{c}\text { Duration of } \\
\text { therapeutic effect } \\
(>4.34 \mu \mathrm{g} / \mathrm{mL})\end{array}$ \\
\hline Aqueous-buffered & 80 & $16.19 \pm 3.34$ & 6 days \\
\hline Aqueous-buffered & 40 & $6.49 \pm 1.30$ & 3 days \\
\hline HCQ/HPMC 50:1 & 40 & $1.76 \pm 0.55$ & $\mathrm{n} / \mathrm{a}$ \\
\hline HCQ/HPMC 5:1 & 40 & $0.96 \pm 0.32$ & $\mathrm{n} / \mathrm{a}$ \\
\hline
\end{tabular}

Fig 3. In vivo rabbit study assessing HCQ levels in CVL and vaginal tissues. (a) The rabbit study plan. Rabbits received HCQ implant on day 0 followed by N9 challenge on day 5 for $24 \mathrm{~h}$. Rabbits were sacrificed on day 6 for bioanalysis. Orange arrows indicate the collection of rabbit CVL and blood sampling time points. (b) Comparison of HCQ levels in rabbit CVL during the 6-day study period in animals treated with implants containing either $40 \mathrm{mg}$ or $80 \mathrm{mg}$ HCQ loaded in the presence or absence of the rate-controlling excipient HPMC at different ratios. Dotted line indicates the therapeutic concentration $(4.34 \mu \mathrm{g} / \mathrm{mL}$ or 10 $\mu \mathrm{M}$ of HCQ) for inhibiting T-cell activation ${ }^{23}$. (c) HCQ concentration in different portions of the rabbit vaginal tissue with or without N9 gel challenge. (d) Comparison of the therapeutic effect duration of each tested formulation. Data is expressed as mean $\pm \mathrm{SD}, \mathrm{N}=3$. CVL, cervicovaginal lavage. UV, urovagina; $\mathrm{DC}$, distal cervicovagina; $\mathrm{PC}$, proximal cervicovagina. Data is expressed as mean $\pm \mathrm{SD}, \mathrm{N}=3$. 
a rate of $6.49 \pm 3.55 \mu \mathrm{g} / \mathrm{mL}$ per day, which was above the reported therapeutic concentration of $4.34 \mu \mathrm{g} / \mathrm{mL}$ necessary for T-cell activation suppression [23] and viral inhibition at $6.48 \mu \mathrm{g} / \mathrm{mL}$ [36] which lasted for 3 days. Rabbits that received implants containing $80 \mathrm{mg}$ of aqueous-buffered HCQ demonstrated a gradual decrease in the concentration of HCQ in CVL from $28.43 \pm 3.55$ $\mu \mathrm{g} / \mathrm{mL}$ on day 1 to $7.34 \pm 1.58 \mu \mathrm{g} / \mathrm{mL}$ on day 6 , maintaining a therapeutic effective duration for 6 days with sustained HCQ elution at an average daily rate of $16.19 \pm 3.34 \mu \mathrm{g} / \mathrm{mL}$ (Fig. 3b, d). Therefore, the dosage form with a higher loading (80 mg HCQ) in the absence of HPMC was selected for the N9 challenge study. Mass balance was determined on the residual HCQ remaining in the implants at the end of the study (Day 6) using solvent extraction. Approximately, $30.64 \pm$ $4.22 \%$ of the initial loaded HCQ was remaining within the implant on day 3 followed by approximately $3.09 \pm 0.88 \%$ remaining on day 6 (Fig. S6). Vaginal tissue distribution analysis (Fig. 3c) revealed that HCQ accumulated preferentially in the urovagina (UV, $93.44 \pm 157.71$ $\mathrm{ng} / \mathrm{mg}$ ) portion of the rabbit vagina followed by the distal cervicovagina (DC, $23.06 \pm 38.28 \mathrm{ng} / \mathrm{mg}$ ) and the proximal cervicovagina (PC, $1.53 \pm 1.05 \mathrm{ng} / \mathrm{mg}$ ). Interestingly, animals that received the same implant but challenged with 4\% N9 gel demonstrated a more even distribution of HCQ throughout the rabbit vaginal tract: $43.14 \pm 80.23 \mathrm{ng} / \mathrm{mg}$ in the lower UV section, $57.12 \pm 116.36$ $\mathrm{ng} / \mathrm{mg}$ in the DC section and $31.86 \pm 64.72 \mathrm{ng} / \mathrm{mg}$ in the PC region. During the entire study period, HCQ levels were undetectable (below LLOQ of the utilized HPLC method) in the blood samples collected at different time intervals

\subsection{Suppressed nonoxynol-9 induced vaginal irritation by HCQ implant}

To assess the protective efficacy of our HCQ implant against acute N9-induced tissue inflammation, we investigated lymphocyte recruitment in the stroma and evaluated the 
morphology and integrity of the vaginal epithelium (Fig. 4 and Fig S7 to S9). We also examined the production of key inflammatory biomarkers in either CVL or vaginal tissues (Fig. 5) as these are early mucosal irritation indicators widely evaluated in microbicide toxicity studies [12, 16, 37].

Disruption to vaginal epithelium integrity and increased lymphocyte infiltration in the submucosa was observed in N9 only group throughout the entire vaginal tract (Fig. 4, N9 Only panel). In contrast, no significant differences in the morphology of the vaginal epithelium were observed in of rabbits treated with implants containing HCQ. A reduction in lymphocyte recruitment at the UV, DC, and PC portions was also observed (Fig. 4, N9+HCQ panel), demonstrating the protective effects of HCQ against N9-induced mucosal irritation. In addition, there were no significant differences between the naive, placebo, and HCQ only groups, indicating that the implants did not damage the vaginal epithelium or induce any cell infiltration at the submucosa (Fig. 4)

In this study, we evaluated various biomarkers which represent key cytokines and chemokines involved in inflammation (IL-1 $\beta$, IL-6, IL-8) [18, 37] or lymphocyte infiltration and T-cell activation (IL-8, MIP-3 $\alpha$, TNF- $\alpha$ ) [16]. The production of these markers in both CVL and different sections of the rabbit vaginal tract were compared (Fig. 5). Productions of IL-1 $\beta$, IL-8, and MIP-3 $\alpha$ in vaginal lavage were significantly reduced in rabbits treated with the HCQ-implant and challenged with N9 compared to rabbits that were challenged with N9 alone ( $p<0.0001$, Fig. 5, a, c and d). After N9 exposure, HCQ was able to maintain or reduce IL-8 and MIP-3 $\alpha$ expression to levels similar to basal levels. In agreement with other studies, single N9 treatment did not significantly induce IL-6 production during the acute inflammatory response stage [18] (Fig. 5b). The placebo group and the HCQ implant only control group did not exhibit any significant changes in the expression of the biomarkers in comparison to the naïve group, 

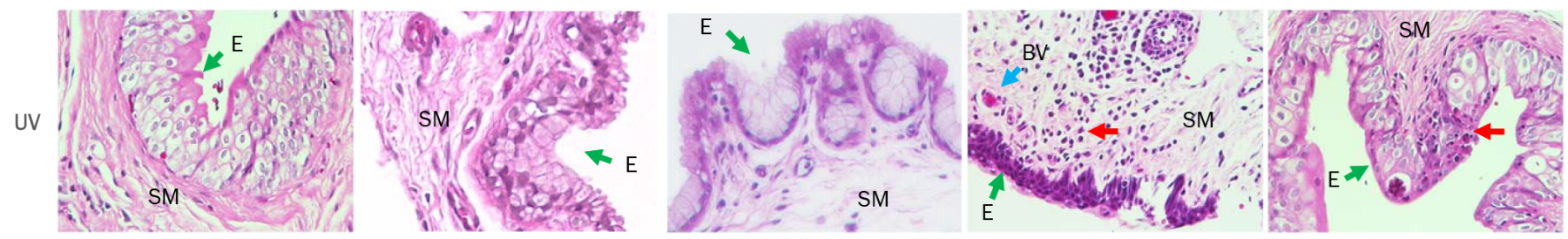

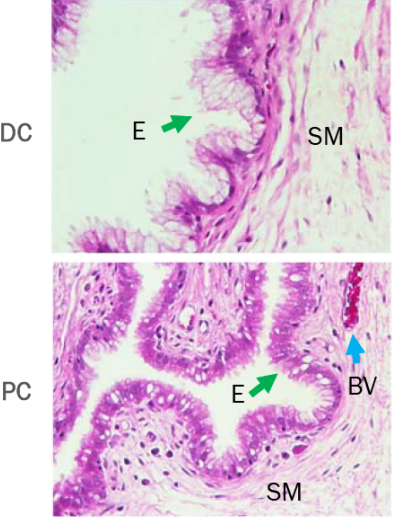

Naïve

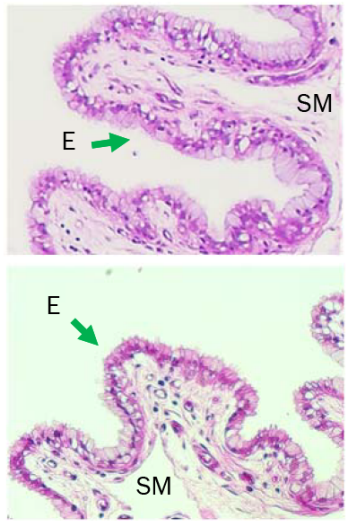

Placebo

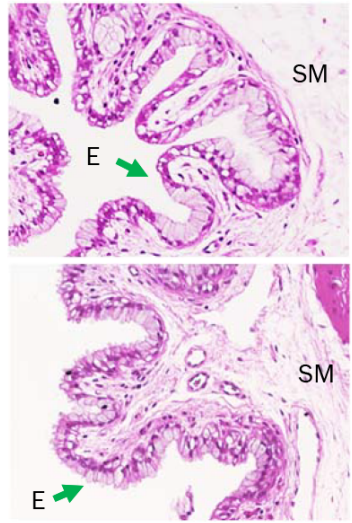

HCQ Only

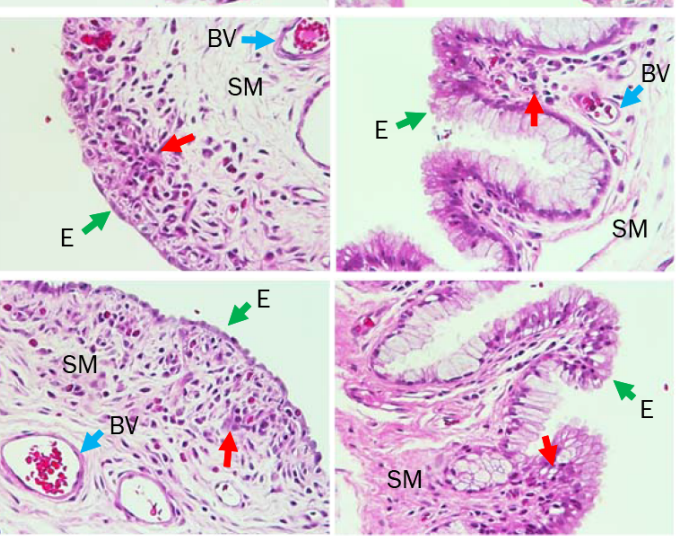

N9 Only

$\mathrm{N} 9+\mathrm{HCQ}$

Fig 4. Rabbit vaginal epithelium morphology after N9 challenge. Representative H\&E stained images of the UV, DC and PC portions of the rabbit vagina. Green arrow indicates the epithelium, red arrow indicates infiltration of lymphocytes in the submucosa, blue arrow indicates the formation of vascular vessels in the stroma. Photos were taken under 400X magnification. E, epithelium; SM, submucosa; BV, blood vessel. 

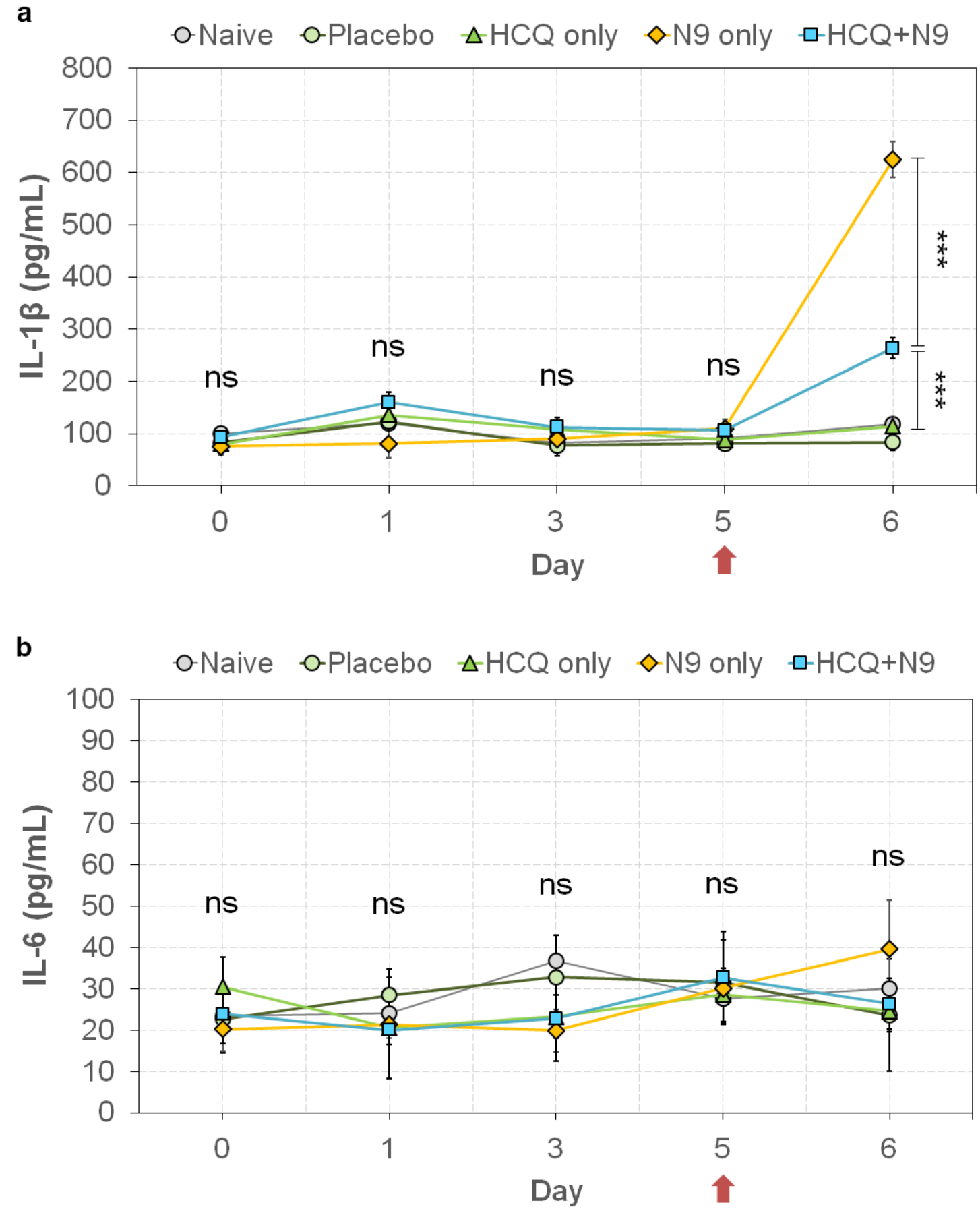

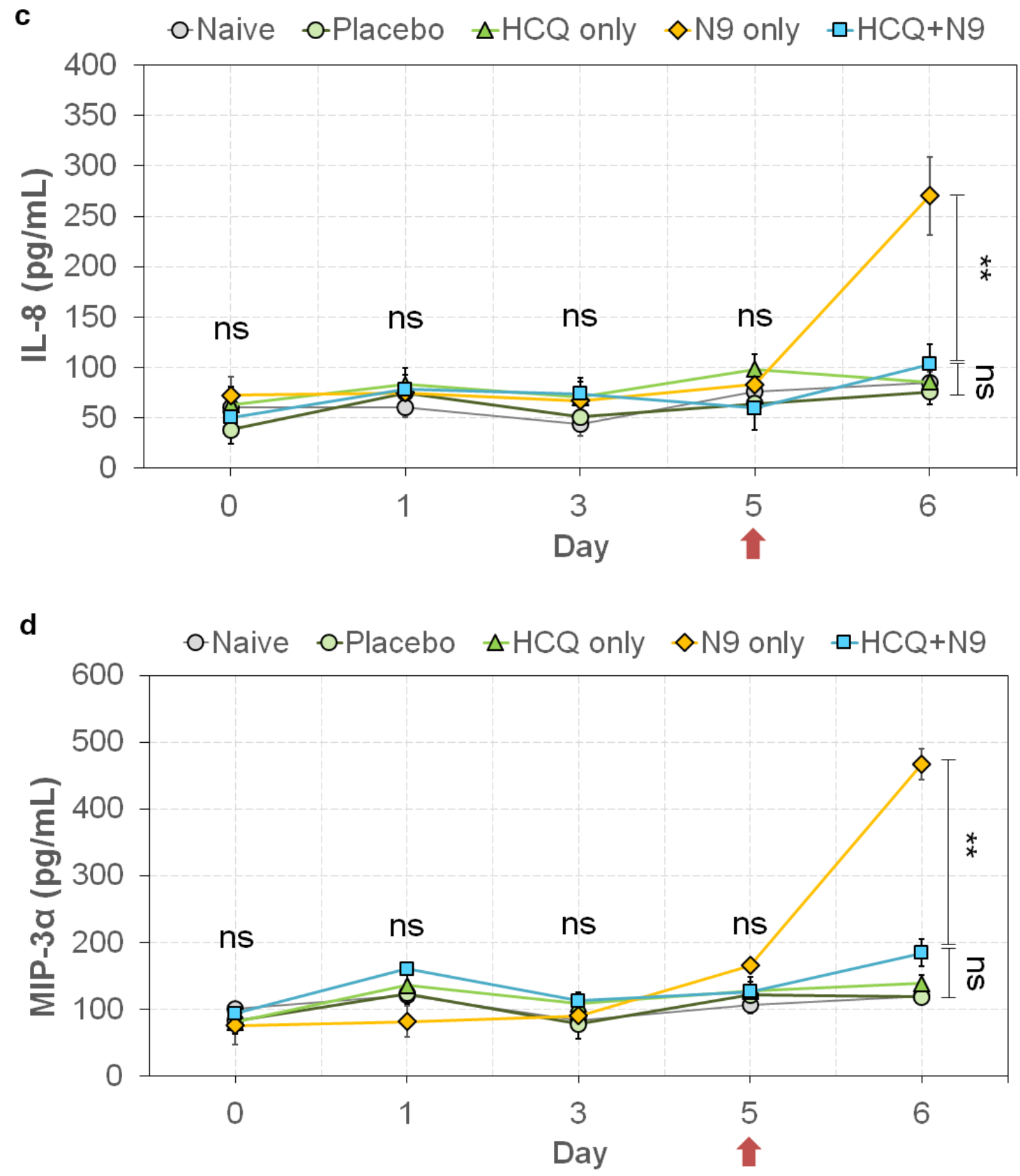

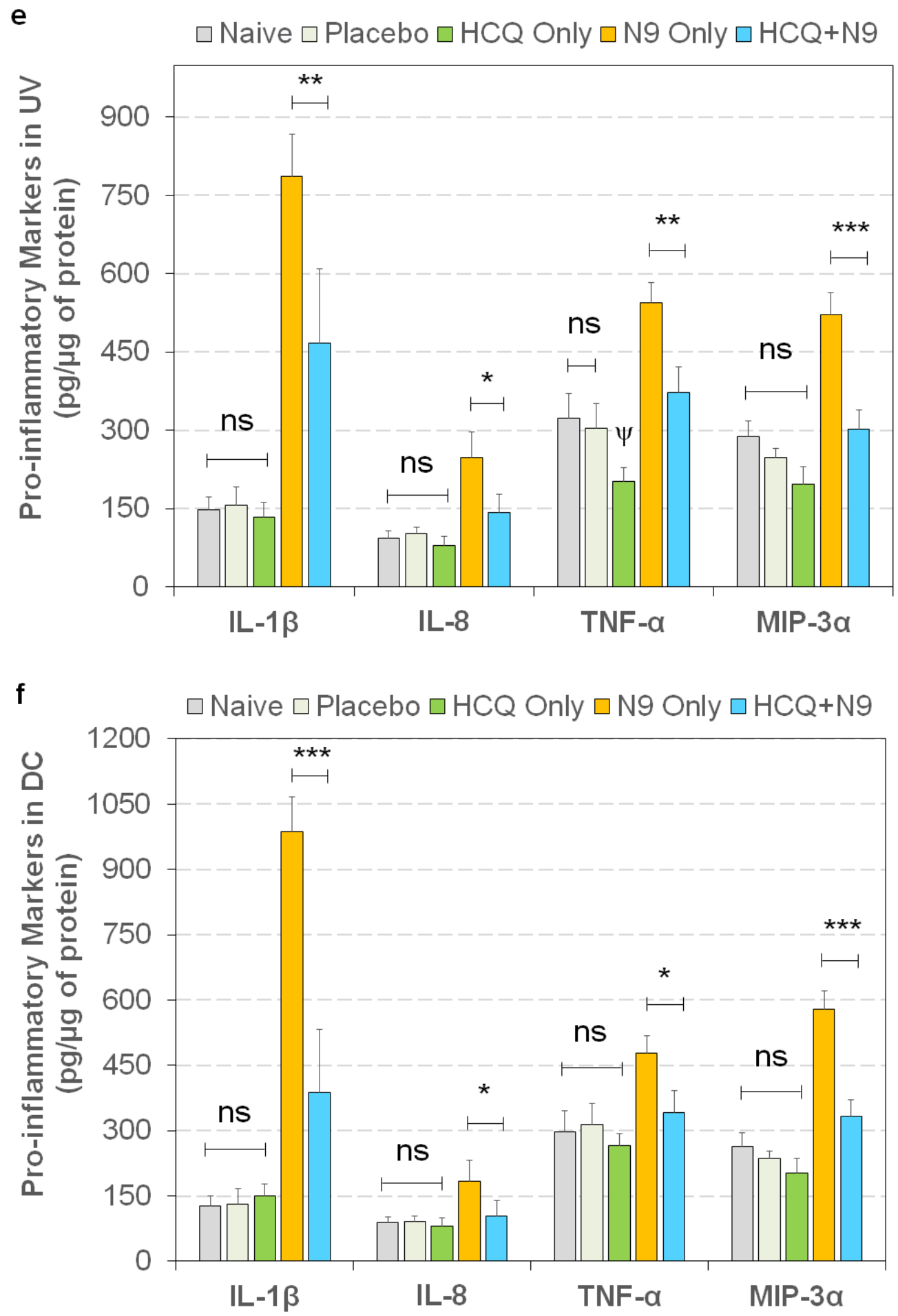


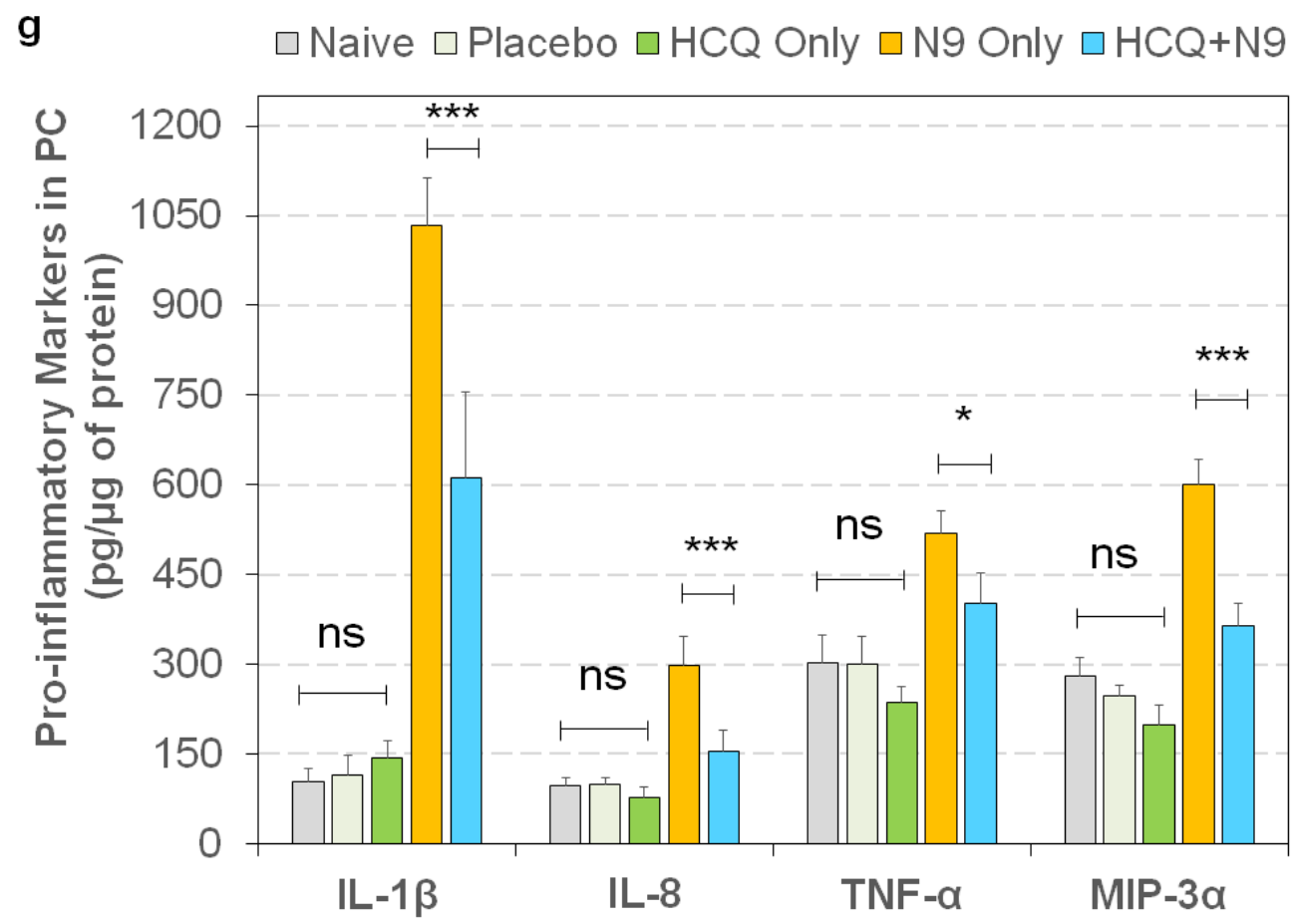

Fig. 5 Representative pro-inflammatory cytokine and chemokine production in rabbit CVL and vaginal tissue (a) IL-1 $\beta$, (b) IL-6, (c) IL-8, and (d) macrophage inflammatory protein-3 alpha (MIP-3 $\alpha$ ) production in rabbit CVL samples. Vaginal N9 challenge was introduced on day 5 after CVL sampling as indicated by the red arrows. Levels in the rabbit CVL were determined by quantitative sandwich ELISAs. IL-1 $\beta$, IL-8, TNF- $\alpha$, and MIP-3 $\alpha$ expression in rabbit (e) urovagina, (f) distal cervicovagina, and (g) proximal cervicovagina. Marker expression levels shown as pg of each inflammatory marker per $\mu \mathrm{g}$ total protein of respective vaginal tissue. All data expressed as mean $\pm \mathrm{SD}, \mathrm{N}=3 ; *: p<0.05 ; * *: p<0.01$; ***: $p<0.001$; ns: no statistical significance. $\Psi: \mathrm{p}<0.05$, in comparison to naïve group. 
confirming the in vivo biocompatibility of this dosage form. Furthermore, quantitation of the early T-cell and macrophage recruitment markers IL-1 $\beta$, IL-8, TNF- $\alpha$, and MIP-3 $\alpha[12,16,37]$ within different sections of the rabbit vaginal tract revealed that their expression were significantly attenuated by HCQ implantation in comparison to the naïve group (Fig. 5, e-g). IL-8, TNF- $\alpha$, and MIP-3 $\alpha$ were significantly attenuated by HCQ implants in all three sections of the rabbit vagina and maintained the baseline expression levels (no significant difference compared to the naïve group), of which MIP-3 $\alpha$ expression was most significantly reduced ( $p<0.001$ in UV, DC, and PC). Rabbits treated with the HCQ implant showed significantly attenuated N9-induced IL$1 \beta$ expression within the entire vaginal tract $(\mathrm{p}<0.01$ in $\mathrm{UV}, \mathrm{p}<0.001$ in $\mathrm{DC}$ and $\mathrm{PC})$. Specifically, the DC portion which was in direct contact with the HCQ implant exhibited the greatest reduction in the expression of IL-1 $\beta$ (60.70\%), IL-8 (55.32\%) and MIP-3 $\alpha(42.48 \%)$ in comparison to rabbits exposed to N9 only. Rabbits treated with the HCQ implant also demonstrated the most significant reduction in TNF- $\alpha$ expression in the UV section of the vaginal tract with a $42.63 \%$ reduction in comparison to N9 only group (p $<0.01$, Fig. 5e).

\subsection{HCQ implant attenuates expression of activation markers on mucosal $T$ lymphocytes during N9 challenge}

In the present study, N9-induced inflammation within the rabbit FGT evidently led to increased immune cell recruitment at the vaginal mucosal surface (Fig. 4) and elevated production of T-cell activation mediators (Fig. 5) including IL-8, MIP-3 $\alpha$, and TNF- $\alpha[16,38]$. Studies have shown that HLA-DR expression is significantly increased in activated CD4+ and CD8+ cervical T cells in HIV-infected women [39]. As a result, we isolated the immune cells from the rabbit vaginal tissue (combined from UV, DC, and PC portions) and utilized flow cytometry to quantitate the expression of RLA-DR (rabbit equivalent of human HLA-DR). We used CD3/CD4/CD8 to define 
$\square$ Naive $\square$ Placebo $\square \mathrm{HCQ}$ only $\square \mathrm{N9}$ only $\square \mathrm{HCQ}+\mathrm{N9}$
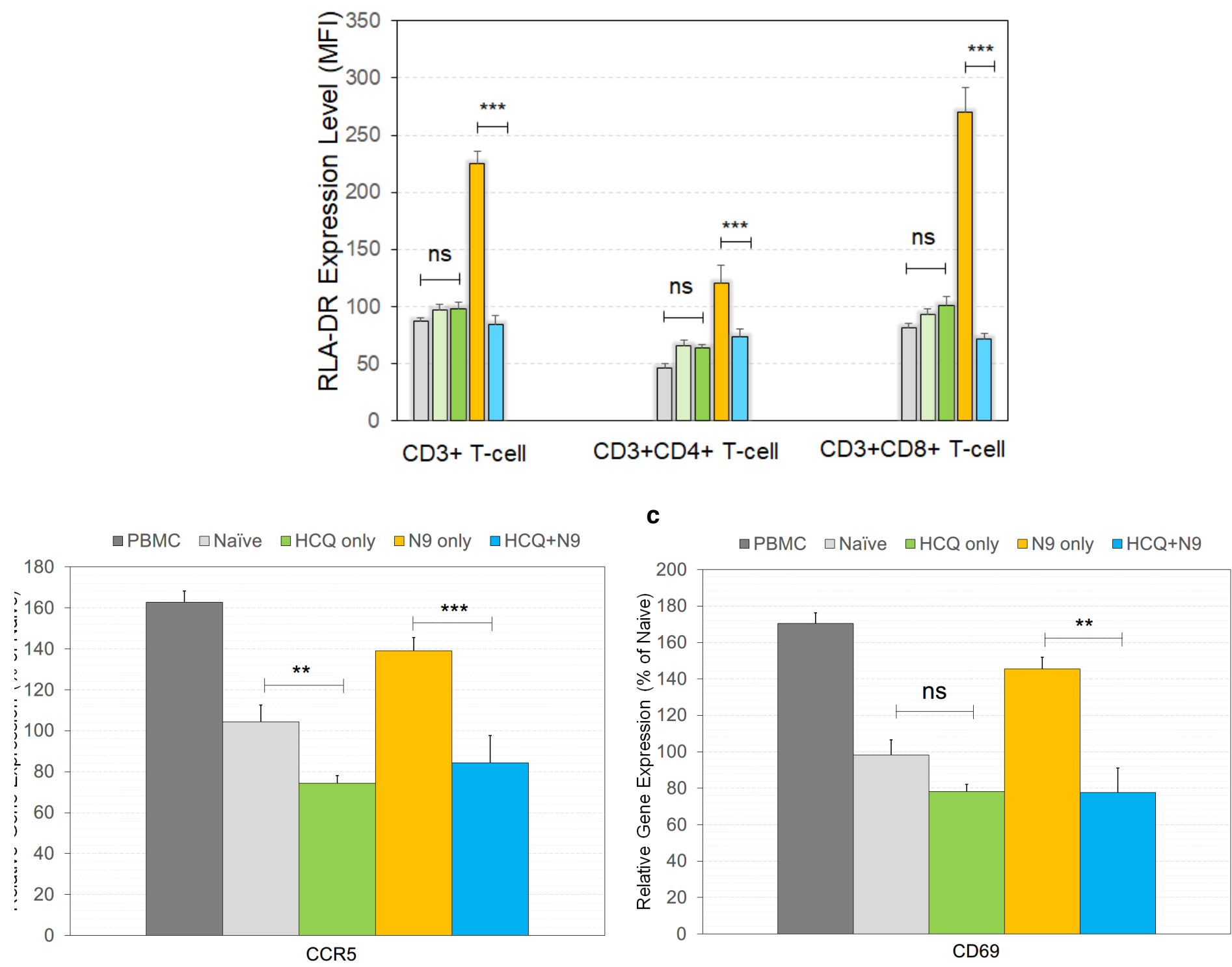

Fig. 6. RLA-DR, CCR5, CD69 expressions on isolated vaginal mucosal T cells. (a) Vaginal mucosal T lymphocytes were isolated from the rabbit vaginal tissue and analyzed via flow cytometry. $\mathrm{T}$ cells were gated based on CD3 expression. Data expressed as mean fluorescent intensity (MFI) of RLA-DR signal per $1 \times 10^{6}$ cells (mean $\pm \mathrm{SD}, \mathrm{N}=3$ ). The normalized mRNA levels of (b) CCR5 and (c) CD69 were assessed using quantitative RT-PCR using $50 \mathrm{ng}$ of total mRNA extracted from the positive-isolated vaginal $\mathrm{T}$ lymphocytes. Isolated rabbit PBMC cells treated with $5 \mu \mathrm{g} / \mathrm{mL}$ of PHA in RPMI-1640 medium for $6 \mathrm{hr}$ were used as positive controls for CCR5 and CD69. Data normalized to naïve group and expressed as relative gene expression with GAPDH being used as endogenous control (mean $\pm \mathrm{SD}, \mathrm{N}=3$ ). ${ }^{* *}: p<0.01$; $* * *: p<0.001$; ns: no statistical significance. 
T-cell subsets. As seen in Fig. 6a, neither HCQ implant nor placebo implant significantly affected RLA-DR expression on isolated $\mathrm{T}$ cells in comparison to naïve group. Rabbits treated with the HCQ implant completely attenuated the induction in RLA-DR expression on both CD4+ and CD8+ T-cell subsets after N9 challenge, maintaining RLA-DR expression on vaginal T cells at baseline levels. Studies demonstrated elevated number of $\mathrm{T}$ cells expressing the early $\mathrm{T}$-cell activation marker CD69 and increased levels of T-cell chemokine co-receptor CCR5 expression to be associated with immune activation at the FGT [40]. Due to the lack of commercially available anti-rabbit CCR5 and CD69 antibodies for flow cytometry, we performed qRT-PCR to determine the mRNA levels of these activation markers in vaginal $\mathrm{T}$ cells using dynabeads conjugated with antibody recognizing rabbit $\mathrm{T}$ cells (Fig. 6, b and c). HCQ implants significantly attenuated the increase in mRNA expression of CCR5 and CD69 in comparison to rabbits challenged with N9 only ( $\mathrm{p}<0.001$ and $\mathrm{p}<0.01$, respectively).

\section{Discussion}

HIV-exposed seronegative (HESN) individuals have revealed a unique phenotype of low baseline immune activation such as reduced expression of CCR5 [41] and T-cell activation markers HLADR [41], CD38 [14], CD69 [42], as well as lowered levels of pro-inflammatory cytokine and chemokine production $[42,43]$. Therefore, if this unique "immune quiescent" state can be pharmacologically induced at the FGT, it will provide an excellent alternative strategy to protect women from HIV infection. In this study, we are the first to demonstrate that HCQ delivered to the FGT via an implant system can maintain a low baseline level of immune activation even after challenge with $\mathrm{N} 9$. 
Female NZW rabbits were selected as our model since its FGT is physiologically similar to human's, they are relatively inexpensive in comparison to nonhuman primates, and they have been widely used to evaluate vaginal products for contraception [44] or microbicides for sexually transmitted infections [30]. The 14 to $19 \mathrm{~cm}$ long rabbit vagina is anatomically similar to the human vagina and is comprised of the lower urovagina (UV, distal section of the vagina) and the proximal cervicovagina (proximal section of the vagina) [45]. The urovagina exhibits stratified squamous epithelium similar to the human vagina and the cervicovagina portion consists of monostratified columnar epithelium which is also similar to the human endocervix [34]. It has been previously shown that vaginal application of N9 in rabbits can severely disrupt epithelial integrity, triggering pro-inflammatory cytokine and chemokine production as well as lymphocyte activation and infiltration [46]. Most importantly, the constitutive presence of T lymphocytes in the rabbit vaginal tract with a reported density of 104-185 cells per $\mathrm{mm}^{2}$ [47] will allow us to evaluate local T-cell activation under N9 exposure. Moreover, the large rabbit vaginal lumen in comparison to rodents is able to accommodate our relatively large polyurethane implant system, making it an inexpensive model to collect important information before translating to nonhuman primate studies or human clinical trials.

Since the focus of this study is to examine vaginal immune activation in the presence of $\mathrm{N} 9$, it is important that all procedures and materials used in the study will not elicit an adverse inflammatory response. As a result, previous invasive methods for studying implants within the FGT such as suturing [10] should be avoided since it not only induces unwanted local inflammation but may also cause unregulated drug penetration directly via the suturing site abolishing normal drug adsorption by healthy vaginal epithelium. In this study, we developed a biocompatible implant and a non-invasive implantation procedure that will allow us to place the 
implant in the appropriate location within the rabbit vaginal cavity (Fig. 2 and Fig. S3) for prolonged periods of time. The chosen dimension of our implant was influenced by previous studies showing that a cross-sectional diameter of approximately $8-10 \mathrm{~mm}$ tubing was well tolerated by female NZW rabbits for vaginal evaluation of therapeutic agents [32]. The hydrophilic PU (with a shore hardness of 42D) utilized in the current study possessed appropriate elastomeric properties, offering adequate flexibility to balance the requirements between the tolerance for slight compression of the implant body during implantation and the proper mechanical stiffness needed for safely retaining the implant within the rabbit vaginal cavity for prolonged periods (Fig. 2c). To non-invasively monitor vaginal residence of the implant, we introduced RFID tags for realtime identification. The medical-grade aliphatic PU used in the study has been shown to demonstrate long-term in vivo biocompatibility in pre-clinical animal studies $[8,35,48]$ and recently in a phase I clinical trial [11]. Our group has also shown that the same PU was biocompatible with vaginal/ectocervical epithelial cells and SupT1 T cells in vitro [26]. Overall, the intravaginal implant described in this work may be adapted to develop other drug-eluting microbicides with rabbits as a suitable model for long-term intravaginal evaluation of therapeutics without causing inflammation locally.

$\mathrm{HCQ}$ is an inexpensive drug with immunomodulatory and antiviral activity $(>4.34 \mu \mathrm{g} / \mathrm{mL})$ $[21,22]$. In addition, at a concentration of $21.7 \mu \mathrm{g} / \mathrm{mL}$, chloroquine was shown to inhibit mitogenstimulated lymphocyte transformation [49]. As a result, our implant system was designed to release HCQ within this therapeutic concentration range, providing a CVL HCQ release rate above 4.34 $\mu \mathrm{g} / \mathrm{mL}$ with longest possible duration but below $21.7 \mu \mathrm{g} / \mathrm{mL}$ to avoid potential interference with normal immune function at FGT (Fig. 3, a and d). During the study period, the rabbit implant was deployed at the DC portion (Fig. 2c and Fig. S3a) of the cervicovagina to avoid potential wash- 
out of the drug content by urine. In our rabbit model, it was observed that HCQ was rapidly depleted from the implant system with high concentrations found in vaginal tissue (Fig. 3, b and c; Fig. S6). It is possible that HCQ was mainly released from the implant via a dissolutioncontrolled mechanism rather than diffusion-controlled [35]. It is also possible that HCQ preferentially accumulates in tissue due to the high water-octanol partition coefficient of HCQ [50] and its high protein-binding affinity[51]. Nevertheless, the levels of HCQ released from the implant and its tissue distribution in the UV and DC portions of the vaginal tract were comparable to the levels of tenofovir and tenofovir disoproxil fumarate observed in previous studies [48]. In contrast, an altered distribution of HCQ within the rabbit FGT was found in rabbits challenged with $1 \mathrm{~mL}$ of $\mathrm{N} 9$ gel (Fig. 3c). Conceptrol ${ }^{\circledR}$ gel, whose spreadibility can be increased in the presence of vaginal fluid [52], was shown to be able to cover $48 \%$ of the human vaginal epithelium in 10 min after a single vaginal application while the females were positioned in a supine posture [53]. Modeling studies demonstrated that complete coating of the $7 \mathrm{~cm}$-long and $3 \mathrm{~cm}$-wide macaque vaginal epithelium may be achieved within $1 \mathrm{hr}$ after applying $1.93 \mathrm{~mL}$ of $1 \%$ tenofovir gel [54]. As a result, it is possible that the introduced N9 gel in the current study may contribute to the increased HCQ accumulation in the DC and PC portions of the rabbit vagina by absorbing the released HCQ and evenly spreading the cervicovaginal lumen. The use of a topical delivery system in the current study and the reported short half-life of HCQ in rabbit blood (10.6 hr) [28] may be some of the reasons that HCQ is undetectable in the blood.

An intact stratified squamous vaginal epithelium and columnar endocervical epithelium at the FGT is critical for maintaining the mucosal barrier against HIV infection [55]. To our knowledge, this is the first study to demonstrate that HCQ is able to prevent N9-induced thinning and disruption of both multi-layered stratified and single-layered columnar vaginal epithelium in 
vivo with significantly reduced immune cell infiltration at the submucosa (Fig. 4). Previous studies have reported that increased cyclooxygenase-2 (COX-2) from vaginal epithelial cells can be induced shortly after low-dose N9 exposure due to the activation of NF-кB and MAPK pathways, triggering PGE2 secretion [56]. The observed reduction in cell infiltration at the submucosa of rabbits treated with HCQ implant (Fig. 4) could be a result of the inhibitory effect of HCQ on COX-2 activity since the CVL HCQ level in the current study was higher than that was required $(10 \mu \mathrm{g} / \mathrm{mL})$ for this effect [57]. Studies have also shown that N9-irritated vaginal epithelium is the production source of key pro-inflammatory mediators $[17,18,58]$ such as IL-1 $\beta$, IL-6, IL-8, TNF$\alpha$, and MIP-3 $\alpha$. These in turn will trigger the activation of the NF- $\mathrm{kB}$ and MAPK pro-inflammatory signal transduction pathways [56]. Viral exposure has also been shown to immediately increase MIP3- $\alpha$ expression in the endocervical epithelium. This chemokine attracts plasmacytoid dendritic cells, which in turn recruits T cells and macrophages [59]. In the present study, protection of the vaginal mucosa by HCQ was revealed through the dramatically attenuated secretion of IL- $1 \beta$, IL8, and MIP-3 $\alpha$ in CVL (Fig. 5). Though IL-6 production can be initiated by IL-1 $\beta$ induced transactivation of NF- $\mathrm{kB}$, a single $24 \mathrm{hr}$ N9 exposure may not be sufficient to significantly increase CVL secretion of IL-6, as previously reported by Fichorova and co-workers [18], which was in agreement with the results observed in the current study. Since the presence of IL-1 $\beta$, IL-8, TNF$\alpha$ and MIP- $3 \alpha$ can result in an influx and activation of HIV-susceptible cells at the vaginal mucosa including T cells [60], macrophages, and Langerhans cells [61], we further assessed the levels of these markers in different sections of the rabbit vagina. Similarly, N9-enhanced protein expression of these mediators in vaginal tissue were mitigated in the presence of HCQ (Fig. 5, e-g). The reduced CVL and tissue levels of IL-1 $1 \beta$, IL- 8 , TNF- $\alpha$, and MIP-3 $\alpha$ observed may be due to the inhibitory activity of HCQ on mRNA production by decreasing mRNA stability [62], blocking of 
the mRNA transcription process [63], interference with the post-translational process from other mononuclear cells and vaginal epithelial cells [64-66] or impact on normal iron metabolism [23, 67].

The observed suppressive effect of HCQ on the expression of the T-cell activation marker RLA-DR may be attributed to the relatively high levels of HCQ tissue distribution and HCQ CVL level delivered from our implant which was capable of maintaining the effective concentration ( $>4.34 \mu \mathrm{g} / \mathrm{mL})$ needed for inhibiting PBMC proliferation upon activation [21] and the concentration $(>8.67 \mu \mathrm{g} / \mathrm{mL}$ ) required for possessing pro-apoptotic effects to selectively remove activated CD4+CD45RO+CD45RA- T cells with significantly less impact on naïve T cells [68]. Furthermore, the reduced TNF- $\alpha$ production by HCQ may also interfere with TNF- $\alpha$-dependent HLA-DR elevation in T cells [38] since it has been previously reported that TNF- $\alpha$ can induce HLA-DR expression in both CD4+ and CD8+ T cells [69]. Therefore, based on our findings, intravaginal delivery of HCQ above the therapeutic threshold (minimal $10 \mu \mathrm{M}$ or $4.34 \mu \mathrm{g} / \mathrm{mL}$ ) and "pre-priming" the vaginal tract with adequate HCQ is necessary to render a robust suppressive effect against acute N9-induced inflammation at the FGT and the expression of T-cell activation marker, HLA-DR. In addition, since HCQ itself demonstrates direct anti-HIV activity by interfering with the gp120 glycosylation process above the concentration of $6.48 \mu \mathrm{g} / \mathrm{mL}$ [36], the HCQ concentration delivered via our implant may offer additional benefits by inhibiting this process. Also, due to the antimicrobial effect of HCQ against bacterial infections [70, 71], the delivery of HCQ at the FGT may therefore offer additional protection without negative effects on the viabilities of normal lactobacilli strains usually observed in healthy FGT [26]. It was reported that the daily dose of HCQ above $200 \mathrm{mg}$ in patients under prolonged treatment ( $>1$ year) may increase the risk of developing neuromyotoxicity [72], renal toxicity [73] or retinopathy concerns 
$[74,75]$, however, due to the fact that we were unable to detect systemic HCQ levels in the collected blood samples during the study period, these systemic side effects are not a concern using the current implant system during the 6-day study.

Since there is a lack of commercially available flow cytometry antibodies for detecting rabbit CCR5 and CD69, we conducted real-time PCR to examine changes in their gene expressions. Real-time PCR results revealed that HCQ was able to attenuate N9-induced upregulation of both CCR5 and CD69 mRNA in the rabbits that were treated with the HCQ implant (Fig. 6, b and c). Previous studies have suggested that HCQ $(>10.85 \mu \mathrm{g} / \mathrm{mL})$ was able to inhibit CD69 expression on T cells in vitro through the disruption of TCR crosslinking-dependent calcium signaling [23]. Although there were no previous studies directly investigating the effect of HCQ treatment on CCR5 and CD69 gene expression, the reduced levels of both genes in the current study may be attributed to the inhibitory effects of HCQ on mRNA stability and the transcription process [62, 63]. In addition, the decreased mRNA levels may be related to the possible binding of HCQ to DNA [76] altering its structure [77], thereby interfering with the accessibility of certain regions on the chromatin resulting in reduced transcriptional activity. Further studies will be needed to investigate the possible molecular mechanisms on inhibiting CD69 and CCR5 gene expression by HCQ.

\section{Conclusions}

In summary, we report a biocompatible implant system capable of prolonged residence within the rabbit vaginal tract for sustained topical release of HCQ. To our knowledge, this is the first study to demonstrate that topical delivery of HCQ is capable of attenuating the protein expression of the 
T-cell activation marker RLA-DR (rabbit equivalent of human HLA-DR) and mRNA expression of CCR5 and CD69 on vaginal mucosal T lymphocytes when challenged with N9. The ability of HCQ to also attenuate the expression of N-9 induced inflammatory markers (IL-1 $\beta$, IL-8, TNF- $\alpha$, MIP-3 $\alpha$ ) within the genital tract and CVL demonstrates the potential of HCQ as a promising drug candidate to maintain a low baseline level of immune activation as a novel strategy for preventing HIV infection.

\section{Acknowledgements}

The current research project was supported in part by an Operating Grant (MOP110981) awarded to Dr. Emmanuel A. Ho from the Canadian Institutes of Health Research (CIHR) and a CIHR Canadian HIV Vaccine Initiative Grant (OCH-126275) awarded to Dr. Keith R. Fowke. Mr. Yufei Chen was supported by a Research Manitoba Graduate Studentship and the Leslie F. Buggy Graduate Scholarship in Pharmacy from the University of Manitoba.

\section{References}

[1] UNAIDS, Fact Sheet - Latest Statistics on the Status of the AIDS Epidemic, (2017).

[2] UNAIDS, Prevention Gap Report, (2016).

[3] UNAIDS, Global AIDS Update, (2016). 
[4] C. Garcia-Moreno, C. Zimmerman, A. Morris-Gehring, L. Heise, A. Amin, N. Abrahams, O. Montoya, P. Bhate-Deosthali, N. Kilonzo, C. Watts, Addressing violence against women: a call to action, Lancet, 385 (2015) 1685-1695.

[5] S. Srikrishna, L. Cardozo, The vagina as a route for drug delivery: a review, Int Urogynecol J, 24 (2013) 537-543.

[6] L.I. J.L. richardson, Routes of drug delivery: case studies (2) The vaginal route of peptide and protein drug delivery, Advanced Drug delivery Reviews, 8 (1992) 341-366.

[7] R.S. Teller, D.C. Malaspina, R. Rastogi, J.T. Clark, I. Szleifer, P.F. Kiser, Controlling the hydration rate of a hydrophilic matrix in the core of an intravaginal ring determines antiretroviral release, J Control Release, 224 (2016) 176-183.

[8] J.M. Smith, R. Rastogi, R.S. Teller, P. Srinivasan, P.M. Mesquita, U. Nagaraja, J.M. McNicholl, R.M. Hendry, C.T. Dinh, A. Martin, B.C. Herold, P.F. Kiser, Intravaginal ring eluting tenofovir disoproxil fumarate completely protects macaques from multiple vaginal simian-HIV challenges, Proc Natl Acad Sci U S A, 110 (2013) 16145-16150.

[9] P.F. McKay, J.F. Mann, A. Pattani, V. Kett, Y. Aldon, D. King, R.K. Malcolm, R.J. Shattock, Intravaginal immunisation using a novel antigen-releasing ring device elicits robust vaccine antigen-specific systemic and mucosal humoral immune responses, J Control Release, 249 (2017) $74-83$.

[10] M.R. Clark, P.F. Kiser, A. Loxley, C. McConville, R.K. Malcolm, D.R. Friend, Pharmacokinetics of UC781-loaded intravaginal ring segments in rabbits: a comparison of polymer matrices, Drug Deliv Transl Res, 1 (2011) 238-246.

[11] M.J. Keller, P.M. Mesquita, M.A. Marzinke, R. Teller, L. Espinoza, J.M. Atrio, Y. Lo, B. Frank, S. Srinivasan, D.N. Fredricks, L. Rabe, P.L. Anderson, C.W. Hendrix, P.F. Kiser, B.C. 
Herold, A phase 1 randomized placebo-controlled safety and pharmacokinetic trial of a tenofovir disoproxil fumarate vaginal ring, AIDS, 30 (2016) 743-751.

[12] L. Li, Y. Ben, S. Yuan, A. Liu, H. Wu, J. Xu, X. Zhang, Recruitment of HIV-1 target cells at topical mucosal sites: a sensitive and early marker for determining the safety of microbicide candidates, Emerg Microbes Infect, 2 (2013) e42.

[13] C.M. Card, T.B. Ball, K.R. Fowke, Immune quiescence: a model of protection against HIV infection, Retrovirology, 10 (2013) 141.

[14] M. Camara, T.N. Dieye, M. Seydi, A.A. Diallo, M. Fall, P.A. Diaw, P.S. Sow, S. Mboup, L. Kestens, W. Jennes, Low-level CD4+ T cell activation in HIV-exposed seronegative subjects: influence of gender and condom use, J Infect Dis, 201 (2010) 835-842.

[15] M.P. Holmes KK, Sparling PF, Weisner PJ, Sexually transmitted diseases. 2nd ed, McGrawHill, (1990) 1087-1094.

[16] K. Smith-McCune, J.C. Chen, R.M. Greenblatt, U. Shanmugasundaram, B.L. Shacklett, J.F. Hilton, B. Johnson, J.C. Irwin, L.C. Giudice, Unexpected Inflammatory Effects of Intravaginal Gels (Universal Placebo Gel and Nonoxynol-9) on the Upper Female Reproductive Tract: A Randomized Crossover Study, PLoS One, 10 (2015) e0129769.

[17] R.N. Fichorova, L.D. Tucker, D.J. Anderson, The molecular basis of nonoxynol-9-induced vaginal inflammation and its possible relevance to human immunodeficiency virus type 1 transmission, J Infect Dis, 184 (2001) 418-428.

[18] R.N. Fichorova, M. Bajpai, N. Chandra, J.G. Hsiu, M. Spangler, V. Ratnam, G.F. Doncel, Interleukin (IL)-1, IL-6, and IL-8 predict mucosal toxicity of vaginal microbicidal contraceptives, Biol Reprod, 71 (2004) 761-769. 
[19] J. Stephenson, Widely used spermicide may increase, not decrease, risk of HIV transmission, JAMA, 284 (2000) 949.

[20] B. Bothwell, D.E. Furst, Hydroxychloroquine, Springer, (2005) 81-92.

[21] A. Savarino, L. Gennero, H.C. Chen, D. Serrano, F. Malavasi, J.R. Boelaert, K. Sperber, AntiHIV effects of chloroquine: mechanisms of inhibition and spectrum of activity, AIDS, 15 (2001) 2221-2229.

[22] S. Piconi, S. Parisotto, G. Rizzardini, S. Passerini, R. Terzi, B. Argenteri, P. Meraviglia, A. Capetti, M. Biasin, D. Trabattoni, M. Clerici, Hydroxychloroquine drastically reduces immune activation in HIV-infected, antiretroviral therapy-treated immunologic nonresponders, Blood, 118 (2011) 3263-3272.

[23] F.D. Goldman, A.L. Gilman, C. Hollenback, R.M. Kato, B.A. Premack, D.J. Rawlings, Hydroxychloroquine inhibits calcium signals in $\mathrm{T}$ cells: a new mechanism to explain its immunomodulatory properties, Blood, 95 (2000) 3460-3466.

[24] J.M. Jacobson, S.E. Bosinger, M. Kang, P. Belaunzaran-Zamudio, R.M. Matining, C.C. Wilson, C. Flexner, B. Clagett, J. Plants, S. Read, L. Purdue, L. Myers, L. Boone, P. Tebas, P. Kumar, D. Clifford, D. Douek, G. Silvestri, A.L. Landay, M.M. Lederman, The Effect of Chloroquine on Immune Activation and Interferon Signatures Associated with HIV-1, AIDS Res Hum Retroviruses, 32 (2016) 636-647.

[25] Y. Chen, Y.L. Traore, A. Li, K.R. Fowke, E.A. Ho, Development of polyether urethane intravaginal rings for the sustained delivery of hydroxychloroquine, Drug Des Devel Ther, 8 (2014) 1801-1815. 
[26] Y.L. Traore, Y. Chen, A.M. Bernier, E.A. Ho, Impact of Hydroxychloroquine-Loaded Polyurethane Intravaginal Rings on Lactobacilli, Antimicrob Agents Chemother, 59 (2015) 76807686.

[27] P. Volin, Simple and specific reversed-phase liquid chromatographic method with diode-array detection for simultaneous determination of serum hydroxychloroquine, chloroquine and some corticosteroids, J Chromatogr B Biomed Appl, 666 (1995) 347-353.

[28] I. Gonzalez-Hernandez, L. Aguirre-Cruz, J. Sotelo, R. Lopez-Arellano, A. Morales-Hipolito, H. Jung-Cook, Distribution of hydroxychloroquine in lymphoid tissue in a rabbit model for HIV infection, Antimicrob Agents Chemother, 58 (2014) 584-586.

[29] J. Jiang, K.A. Kelly, Isolation of lymphocytes from mouse genital tract mucosa, J Vis Exp, (2012) e4391.

[30] J.T. Clark, M.R. Clark, N.B. Shelke, T.J. Johnson, E.M. Smith, A.K. Andreasen, J.S. Nebeker, J. Fabian, D.R. Friend, P.F. Kiser, Engineering a segmented dual-reservoir polyurethane intravaginal ring for simultaneous prevention of HIV transmission and unwanted pregnancy, PLoS One, 9 (2014) e88509.

[31] M. Gunawardana, M.M. Baum, T.J. Smith, J.A. Moss, An intravaginal ring for the sustained delivery of antibodies, J Pharm Sci, 103 (2014) 3611-3620.

[32] R.S. Teller, R. Rastogi, T.J. Johnson, M.J. Blair, R.W. Hitchcock, P.F. Kiser, Intravaginal flux controlled pump for sustained release of macromolecules, Pharm Res, 31 (2014) 2344-2353. [33] A. Weissbrod, A. Shapiro, G. Vasserman, L. Edry, M. Dayan, A. Yitzhaky, L. Hertzberg, O. Feinerman, T. Kimchi, Automated long-term tracking and social behavioural phenotyping of animal colonies within a semi-natural environment, Nat Commun, 4 (2013) 2018. 
[34] F. Barberini, F. De Santis, S. Correr, P.M. Motta, The mucosa of the rabbit vagina: a proposed experimental model for correlated morphofunctional studies in humans, Eur J Obstet Gynecol Reprod Biol, 44 (1992) 221-227.

[35] M. Clark, T. Johnson, R. McCabe, J. Clark, A. Tuitupou, H. Elgendy, D. Friend, P. Kiser, A hot-melt extruded intravaginal ring for the sustained delivery of the antiretroviral microbicide UC781, Journal of pharmaceutical sciences, 101 (2012) 576-587.

[36] W.P. Tsai, P.L. Nara, H.F. Kung, S. Oroszlan, Inhibition of human immunodeficiency virus infectivity by chloroquine, AIDS Res Hum Retroviruses, 6 (1990) 481-489.

[37] S. Fields, B. Song, B. Rasoul, J. Fong, M.G. Works, K. Shew, Y. Yiu, J. Mirsalis, A. D'Andrea, New candidate biomarkers in the female genital tract to evaluate microbicide toxicity, PLoS One, 9 (2014) e110980.

[38] M. Hurme, M. Sihvola, Cytokine modulation of HLA-DR expression on proliferating cord blood T cells, Immunol Lett, 20 (1989) 217-222.

[39] H.B. Jaspan, L. Liebenberg, W. Hanekom, W. Burgers, D. Coetzee, A.L. Williamson, F. Little, L. Myer, R.W. Coombs, D. Sodora, J.A. Passmore, Immune activation in the female genital tract during HIV infection predicts mucosal CD4 depletion and HIV shedding, J Infect Dis, 204 (2011) $1550-1556$.

[40] S.Z. Jaumdally, A. Picton, C.T. Tiemessen, M. Paximadis, H.B. Jaspan, H. Gamieldien, L. Masson, D. Coetzee, A.L. Williamson, F. Little, P.P. Gumbi, J.S. Passmore, CCR5 expression, haplotype and immune activation in protection from infection in HIV-exposed uninfected individuals in HIV-serodiscordant relationships, Immunology, 151 (2017) 464-473.

[41] E. Begaud, L. Chartier, V. Marechal, J. Ipero, J. Leal, P. Versmisse, G. Breton, A. Fontanet, C. Capoulade-Metay, H. Fleury, F. Barre-Sinoussi, D. Scott-Algara, G. Pancino, Reduced CD4 T 
cell activation and in vitro susceptibility to HIV-1 infection in exposed uninfected Central Africans, Retrovirology, 3 (2006) 35.

[42] J. Lajoie, J. Juno, A. Burgener, S. Rahman, K. Mogk, C. Wachihi, J. Mwanjewe, F.A. Plummer, J. Kimani, T.B. Ball, K.R. Fowke, A distinct cytokine and chemokine profile at the genital mucosa is associated with HIV-1 protection among HIV-exposed seronegative commercial sex workers, Mucosal Immunol, 5 (2012) 277-287.

[43] D. Chege, Y. Chai, S. Huibner, T. Kain, C. Wachihi, M. Kimani, S. Barasa, L.R. McKinnon, F.K. Muriuki, A. Kariri, W. Jaoko, O. Anzala, J. Kimani, T.B. Ball, F.A. Plummer, R. Kaul, Blunted IL17/IL22 and pro-inflammatory cytokine responses in the genital tract and blood of HIVexposed, seronegative female sex workers in Kenya, PLoS One, 7 (2012) e43670.

[44] G.E. Costin, H.A. Raabe, R. Priston, E. Evans, R.D. Curren, Vaginal irritation models: the current status of available alternative and in vitro tests, Altern Lab Anim, 39 (2011) 317-337.

[45] P.G. Rebollar, Factors affecting efficacy of intravaginal administration of GnRH analogues for ovulation induction in rabbit does, Proceedings of Giornate di Coniglicoltura ASIC, (2011) 3545.

[46] S.L. Hillier, T. Moench, R. Shattock, R. Black, P. Reichelderfer, F. Veronese, In vitro and in vivo: the story of nonoxynol 9, J Acquir Immune Defic Syndr, 39 (2005) 1-8.

[47] W.Y. Gu, P. Janssens, M. Holland, R. Seamark, P. Kerr, Lymphocytes and MHC class II positive cells in the female rabbit reproductive tract before and after ovulation, Immunology and Cell Biology, 83 (2005) 596-606.

[48] T. Johnson, M. Clark, T. Albright, J. Nebeker, A. Tuitupou, J. Clark, J. Fabian, R. McCabe, N. Chandra, G. Doncel, D. Friend, P. Kiser, A 90-day tenofovir reservoir intravaginal ring for mucosal HIV prophylaxis, Antimicrobial agents and chemotherapy, 56 (2012) 6272-6283. 
[49] G. Salmeron, P.E. Lipsky, Immunosuppressive potential of antimalarials, Am J Med, 75 (1983) $19-24$.

[50] D.C. Warhurst, J.C. Steele, I.S. Adagu, J.C. Craig, C. Cullander, Hydroxychloroquine is much less active than chloroquine against chloroquine-resistant Plasmodium falciparum, in agreement with its physicochemical properties, J Antimicrob Chemother, 52 (2003) 188-193.

[51] D.E. Furst, Pharmacokinetics of hydroxychloroquine and chloroquine during treatment of rheumatic diseases, Lupus, 5 Suppl 1 (1996) S11-15.

[52] A.R. Geonnotti, J.J. Peters, D.F. Katz, Erosion of microbicide formulation coating layers: effects of contact and shearing with vaginal fluid or semen, J Pharm Sci, 94 (2005) 1705-1712. [53] M.H. Henderson, G.M. Couchman, D.K. Walmer, J.J. Peters, D.H. Owen, M.A. Brown, M.L. Lavine, D.F. Katz, Optical imaging and analysis of human vaginal coating by drug delivery gels, Contraception, 75 (2007) 142-151.

[54] D.F. Katz, A. Yuan, Y. Gao, Vaginal drug distribution modeling, Adv Drug Deliv Rev, 92 (2015) 2-13.

[55] M. Pope, A.T. Haase, Transmission, acute HIV-1 infection and the quest for strategies to prevent infection, Nat Med, 9 (2003) 847-852.

[56] I.A. Zalenskaya, O.G. Cerocchi, T. Joseph, M.A. Donaghay, S.D. Schriver, G.F. Doncel, Increased COX-2 expression in human vaginal epithelial cells exposed to nonoxynol-9, a vaginal contraceptive microbicide that failed to protect women from HIV-1 infection, Am J Reprod Immunol, 65 (2011) 569-577.

[57] E. Ben-Chetrit, R. Fischel, B. Hinz, M. Levy, The effects of colchicine and hydroxychloroquine on the cyclo-oxygenases COX-1 and COX-2, Rheumatol Int, 25 (2005) 332335. 
[58] I.A. Zalenskaya, T. Joseph, J. Bavarva, N. Yousefieh, S.S. Jackson, T. Fashemi, H.S. Yamamoto, R. Settlage, R.N. Fichorova, G.F. Doncel, Gene Expression Profiling of Human Vaginal Cells In Vitro Discriminates Compounds with Pro-Inflammatory and Mucosa-Altering Properties: Novel Biomarkers for Preclinical Testing of HIV Microbicide Candidates, PLoS One, 10 (2015) e0128557.

[59] A.T. Haase, Targeting early infection to prevent HIV-1 mucosal transmission, Nature, 464 (2010) 217-223.

[60] N. Aziz, R. Detels, L.C. Chang, A.W. Butch, Macrophage Inflammatory Protein-3 Alpha (MIP-3alpha)/CCL20 in HIV-1-Infected Individuals, J AIDS Clin Res, 7 (2016) 587.

[61] W. Berlier, M. Cremel, H. Hamzeh, R. Levy, F. Lucht, T. Bourlet, B. Pozzetto, O. Delezay, Seminal plasma promotes the attraction of Langerhans cells via the secretion of CCL20 by vaginal epithelial cells: involvement in the sexual transmission of HIV, Hum Reprod, 21 (2006) 11351142.

[62] C.H. Jang, J.H. Choi, M.S. Byun, D.M. Jue, Chloroquine inhibits production of TNF-alpha, IL-1beta and IL-6 from lipopolysaccharide-stimulated human monocytes/macrophages by different modes, Rheumatology (Oxford), 45 (2006) 703-710.

[63] S.M. Weber, S.M. Levitz, Chloroquine interferes with lipopolysaccharide-induced TNF-alpha gene expression by a nonlysosomotropic mechanism, J Immunol, 165 (2000) 1534-1540.

[64] M.T. Labro, C. Babin-Chevaye, Effects of amodiaquine, chloroquine, and mefloquine on human polymorphonuclear neutrophil function in vitro, Antimicrob Agents Chemother, 32 (1988) $1124-1130$.

[65] I. Ben-Zvi, S. Kivity, P. Langevitz, Y. Shoenfeld, Hydroxychloroquine: from malaria to autoimmunity, Clin Rev Allergy Immunol, 42 (2012) 145-153. 
[66] S. Picot, F. Peyron, J.P. Vuillez, B. Polack, P. Ambroise-Thomas, Chloroquine inhibits tumor necrosis factor production by human macrophages in vitro, J Infect Dis, 164 (1991) 830.

[67] S. Picot, F. Peyron, A. Donadille, J.P. Vuillez, G. Barbe, P. Ambroisethomas, ChloroquineInduced Inhibition of the Production of Tnf, but Not of Il-6, Is Affected by Disruption of IronMetabolism, Immunology, 80 (1993) 127-133.

[68] J. van Loosdregt, R. Spreafico, M. Rossetti, B.J. Prakken, M. Lotz, S. Albani, Hydroxychloroquine preferentially induces apoptosis of CD45RO+ effector T cells by inhibiting autophagy: a possible mechanism for therapeutic modulation of T cells, J Allergy Clin Immunol, 131 (2013) 1443-1446 e1441.

[69] E. Arva, B. Andersson, Kinetics of cytokine release and expression of lymphocyte cell-surface activation markers after in vitro stimulation of human peripheral blood mononuclear cells with Streptococcus pneumoniae, Scand J Immunol, 49 (1999) 237-243.

[70] J.M. Rolain, P. Colson, D. Raoult, Recycling of chloroquine and its hydroxyl analogue to face bacterial, fungal and viral infections in the 21st century, Int J Antimicrob Agents, 30 (2007) 297308.

[71] R. Wolf, A. Baroni, R. Greco, G. Donnarumma, E. Ruocco, M.A. Tufano, V. Ruocco, Quinine sulfate and bacterial invasion, Ann Clin Microbiol Antimicrob, 1 (2002) 5.

[72] M. Stein, M.J. Bell, L.C. Ang, Hydroxychloroquine neuromyotoxicity, J Rheumatol, 27 (2000) 2927-2931.

[73] M. Bethel, F.M. Yang, S. Li, N.S. Nahman, A.M. Oliver, W. Machua, L.D. Carbone, Hydroxychloroquine in patients with systemic lupus erythematosus with end-stage renal disease, J Investig Med, 64 (2016) 908-910. 
[74] B.N. Phillips, D.W. Chun, Hydroxychloroquine retinopathy after short-term therapy, Retin Cases Brief Rep, 8 (2014) 67-69.

[75] H.J. Ding, A.K. Denniston, V.K. Rao, C. Gordon, Hydroxychloroquine-related retinal toxicity, Rheumatology (Oxford), 55 (2016) 957-967.

[76] H. Schroter, P.E. Shaw, A. Nordheim, Purification of intercalator-released p67, a polypeptide that interacts specifically with the c-fos serum response element, Nucleic Acids Res, 15 (1987) 10145-10158.

[77] U. Zabel, R. Schreck, P.A. Baeuerle, DNA binding of purified transcription factor NF-kappa B. Affinity, specificity, Zn2+ dependence, and differential half-site recognition, J Biol Chem, 266 (1991) 252-260. 


\section{Supplementary figures}

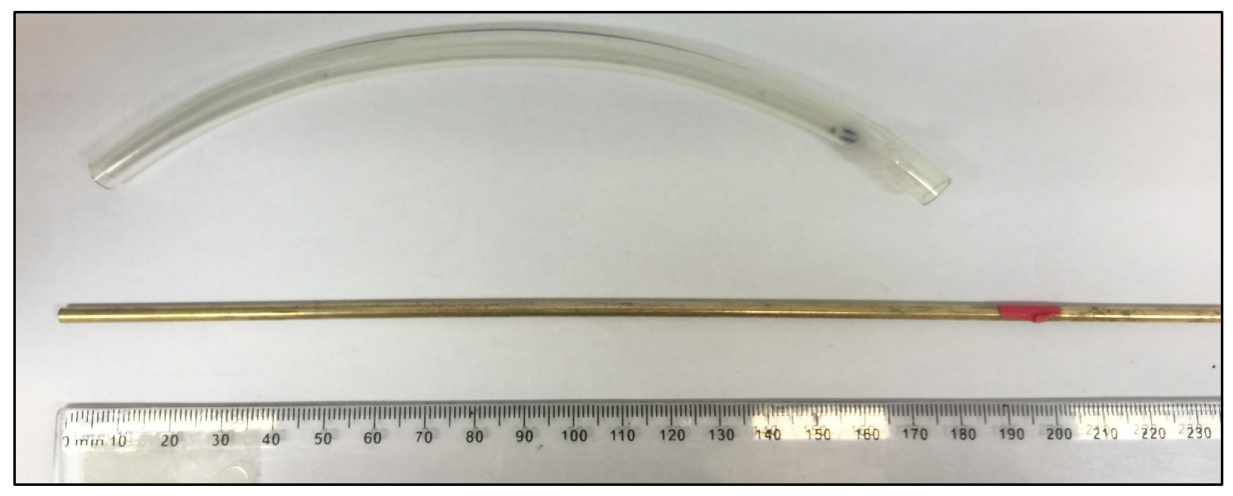

Fig. S1. The medical-grade PU tubing $(7.95 \mathrm{~mm}$ in cross-sectional diameter, $0.78 \mathrm{~mm}$ in wall thickness, 85A shore hardness) and copper rod used for implantation procedure. Units in $\mathrm{mm}$. 

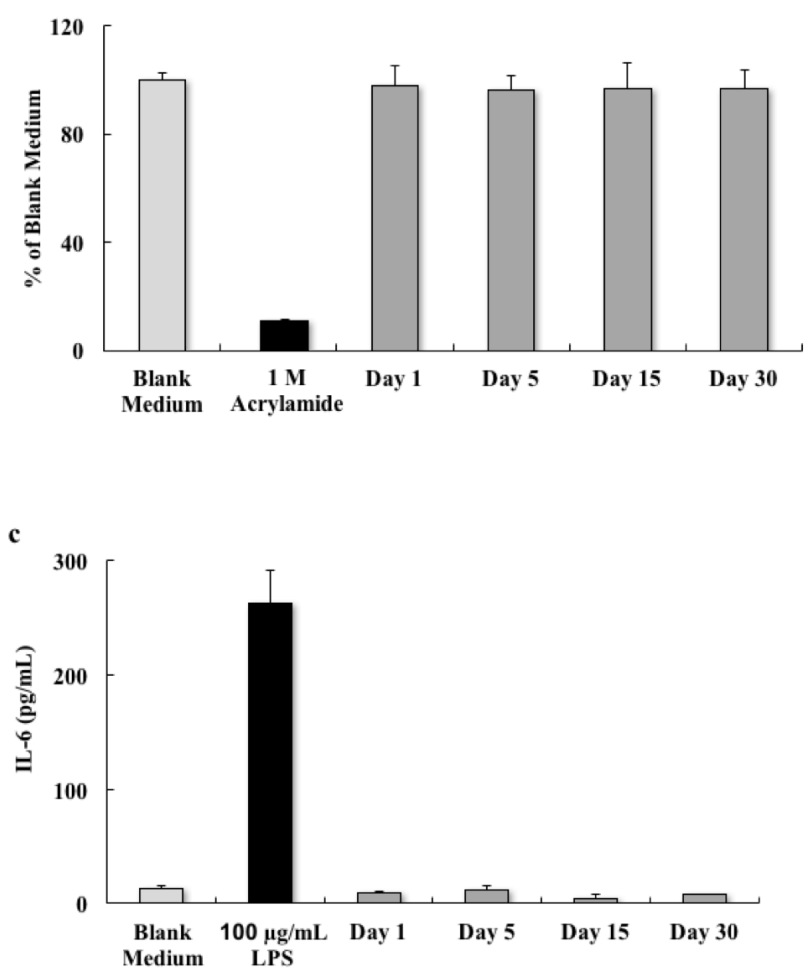

b

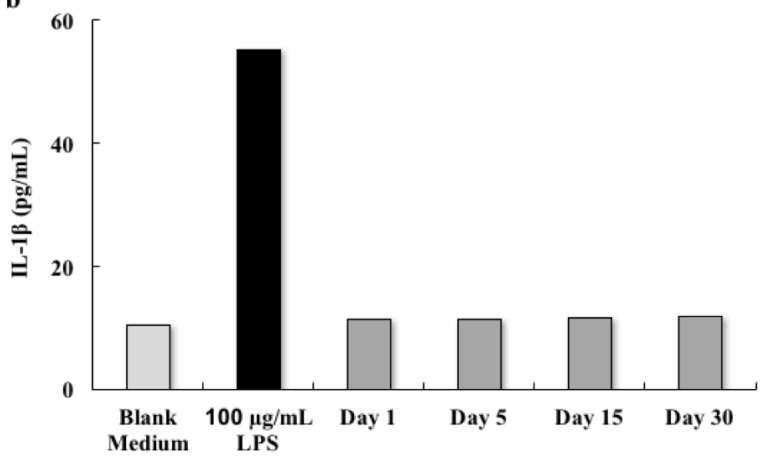

d

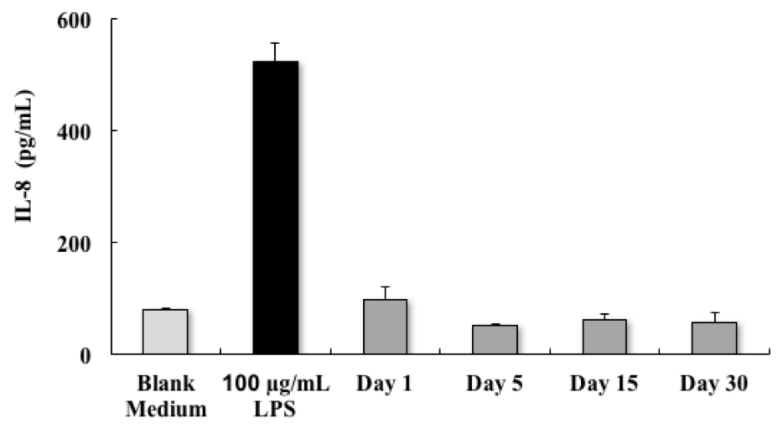

Fig. S2. After solvent casting, two pieces of fabricated implant were sterilized with $70 \%$ alcohol and incubated with $5 \mathrm{~mL}$ keratinocyte-serum free medium using aseptic technique in a biosafety cabinet. The samples were incubated at $37^{\circ} \mathrm{C}$ and $160 \mathrm{rpm}$ for 30 days in an orbital shaker. The eluted medium was incubated with the vaginal epithelial cell line VK2/E6E7 for $24 \mathrm{~h}$. After incubation with eluted medium, cytotoxicity in VK2/E6E7 cells was evaluated using (a) MTS assay and pro-inflammatory cytokine production such as (b) IL-1 $\beta$ (c), IL-6 and (d) IL-8 were quantified using sandwich ELISA. 1 M acrylamide and $100 \mu \mathrm{g} / \mathrm{mL}$ of LPS prepared in culture medium was used to induce cell death as a positive control in MTS assay and cytokine ELISAs, respectively. Cells cultured in blank medium was used as negative control. Data represents $N=6$, mean $\pm S D$. 
a

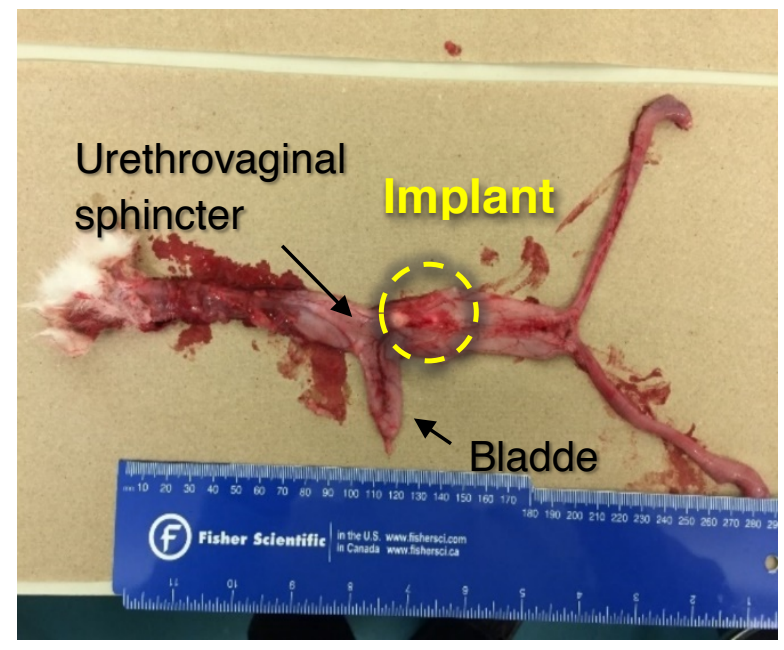

b

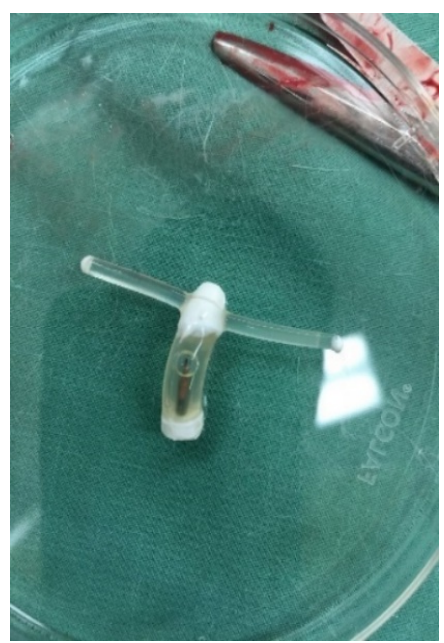

Fig. S3. (a) Representative confirmation of the implant residence after dissection within the cervicovagina of a rabbit 40 days post-implantation. (b) Freshly retrieved HCQ implant from the animal after dissection demonstrated no obvious immune cell adherence or vaginal discharge on the implant surface. 
a

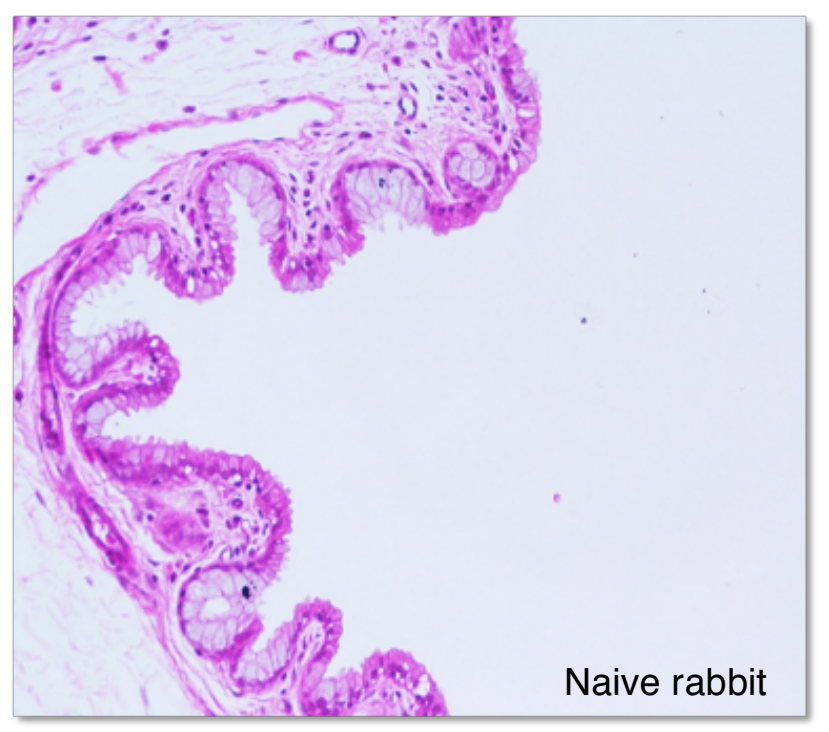

b

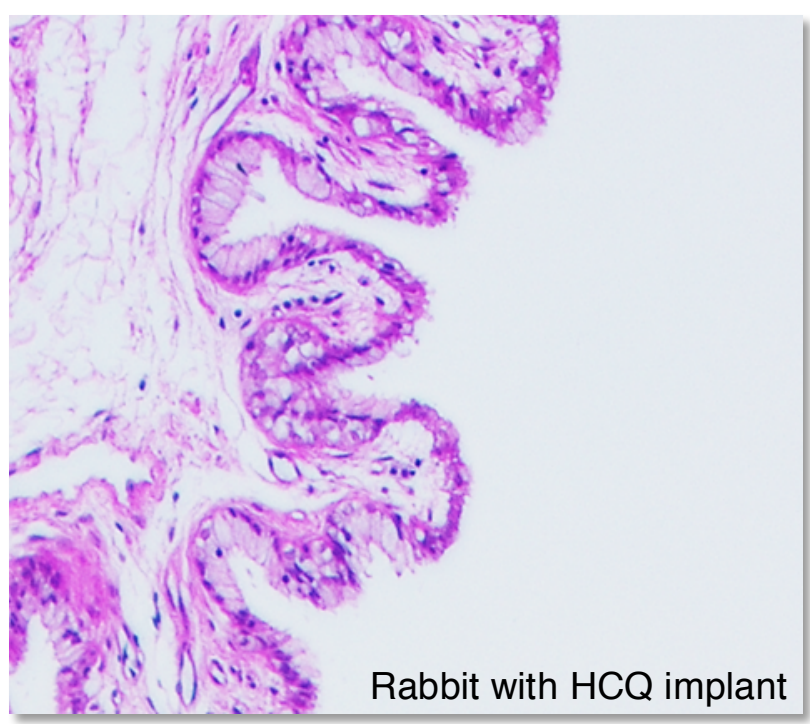

Fig. S4. Representative histological hematoxylin \& eosin staining of the DC vaginal tissue from (a) naive rabbit and (b) rabbit treated with implant containing $40 \mathrm{mg}$ of HCQ after 30 days. Images were acquired at 400X magnification. 
a

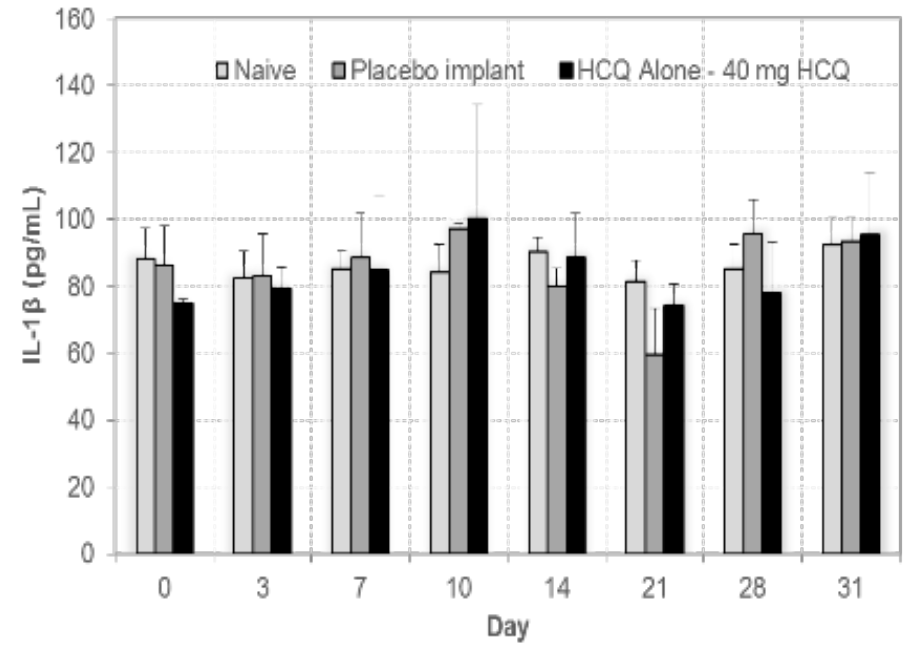

b

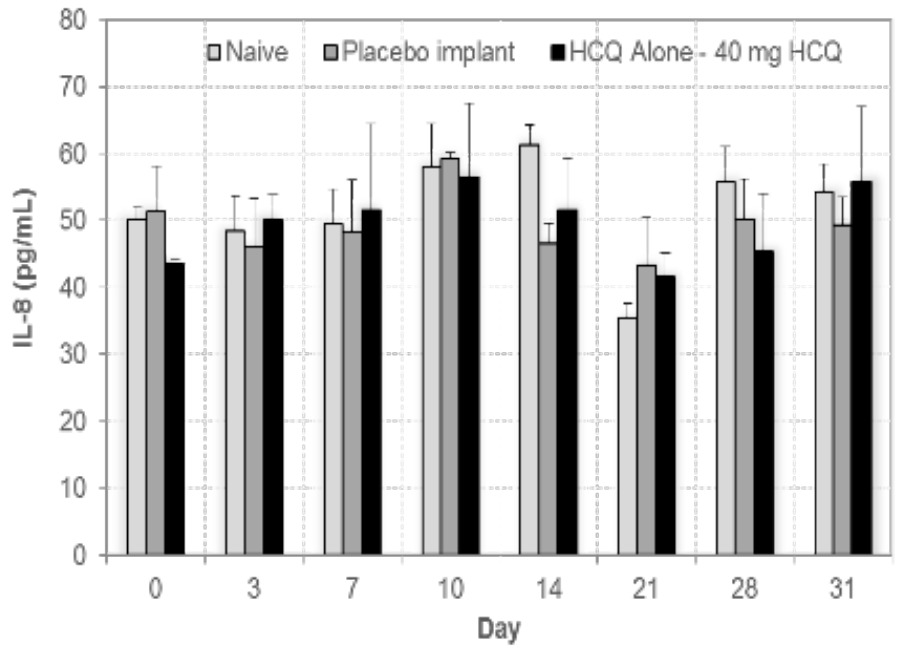

Fig. S5. Cytokine and chemokine concentrations in CVL after 30 days. (a) IL-1 $\beta$ and (b) IL-8. Data represents $\mathrm{N}=3$, mean $\pm \mathrm{SD}$. 


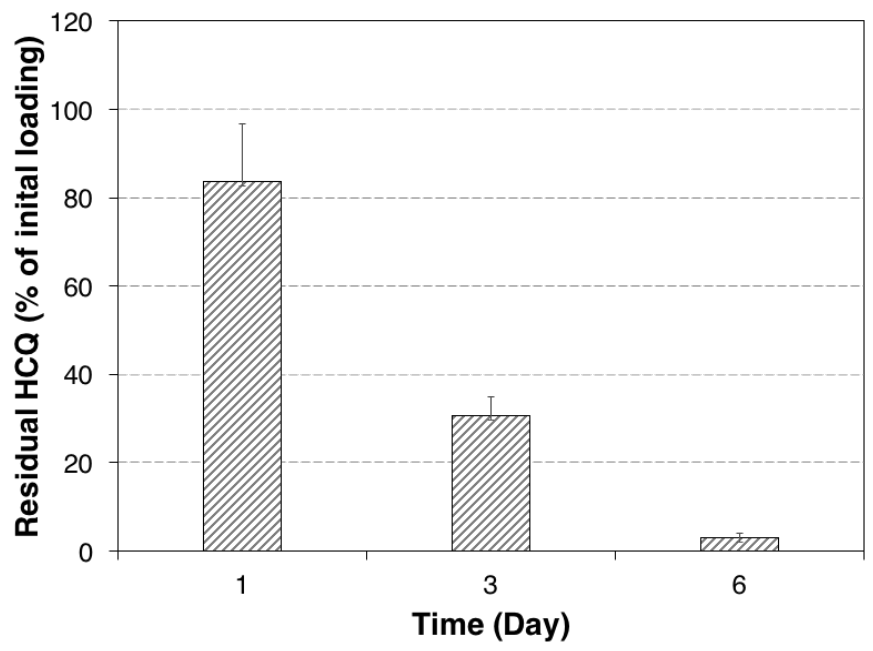

Fig. S6. Assayed residual HCQ content in the retrieved rabbit implant initially loaded with $40 \mathrm{mg}$ of HCQ. Data represents $\mathrm{N}=3$, mean $\pm \mathrm{SD}$. 


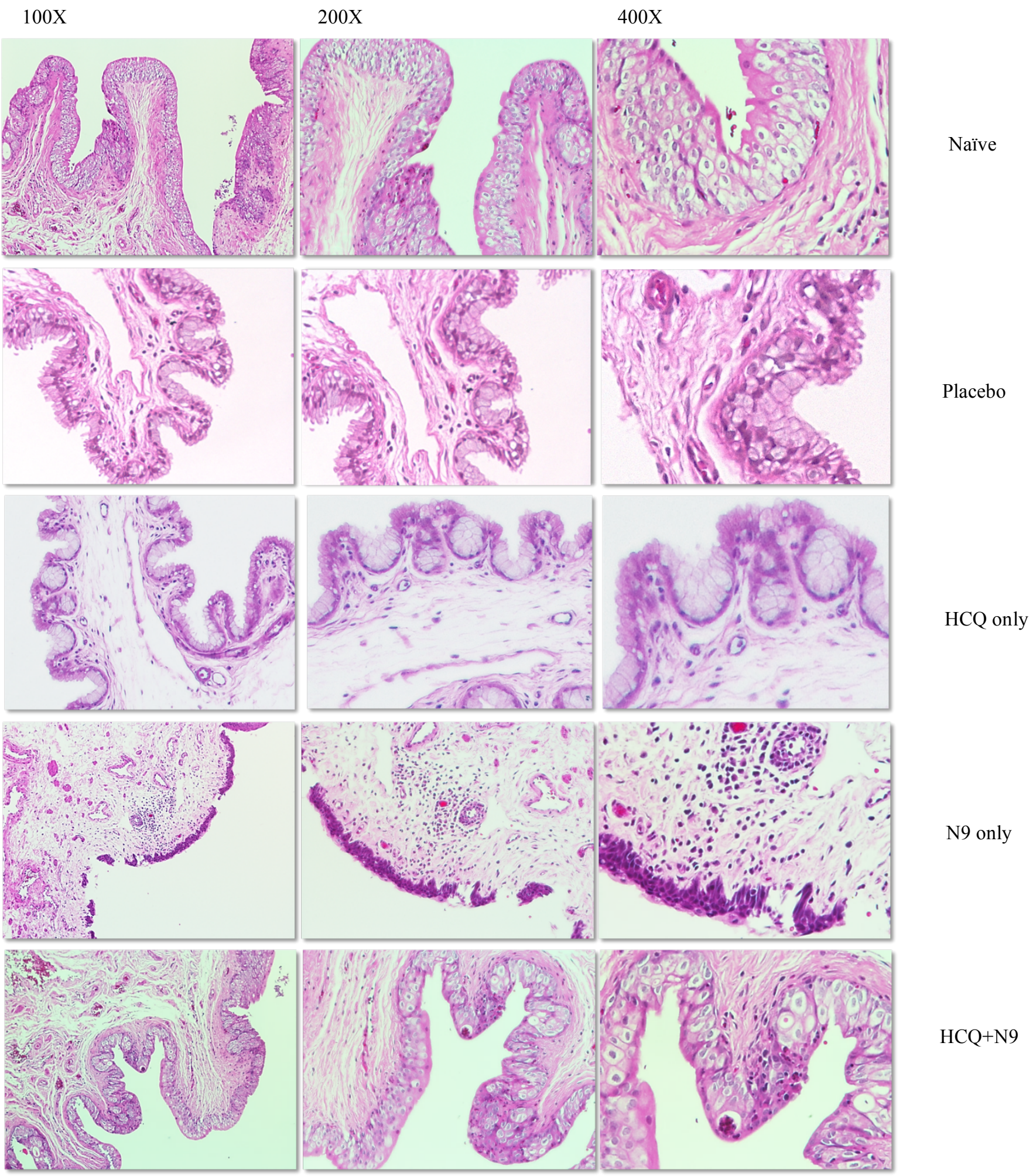

Fig. S7. Representative H\&E staining of the UV sections of rabbits collected on day 6 from naïve group, placebo group, HCQ only group, N9-challenged group, and HCQ implant group with N9 challenge. Images were acquired at 100X, 200X, and 400X magnifications. 


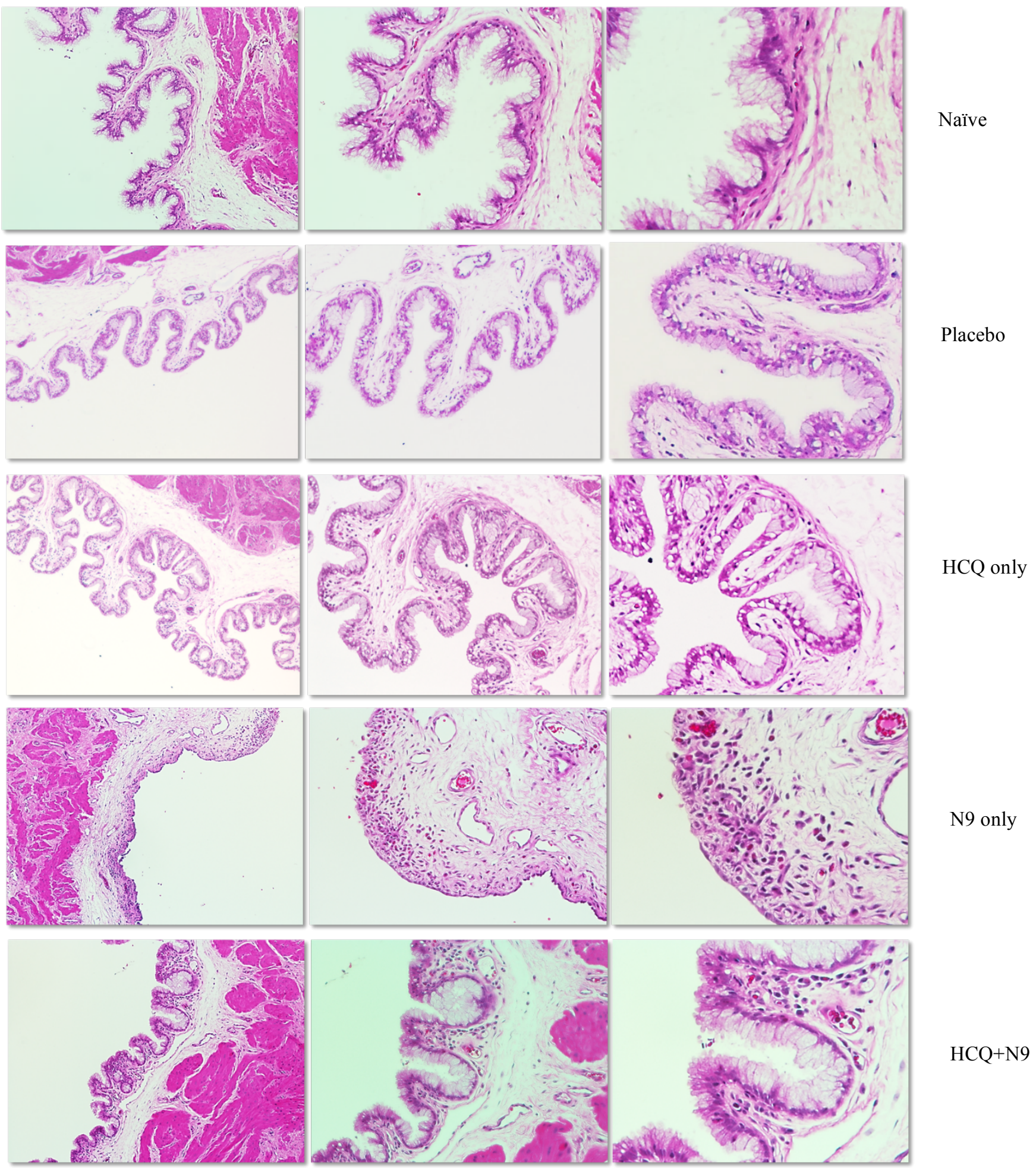

Fig. S8. Representative H\&E staining of the DC sections of rabbits collected on day 6 from naïve group, placebo group, HCQ only group, N9-challenged group, and HCQ implant group with N9 challenge. Images were acquired at $100 \mathrm{X}, 200 \mathrm{X}$, and $400 \mathrm{X}$ magnifications. 


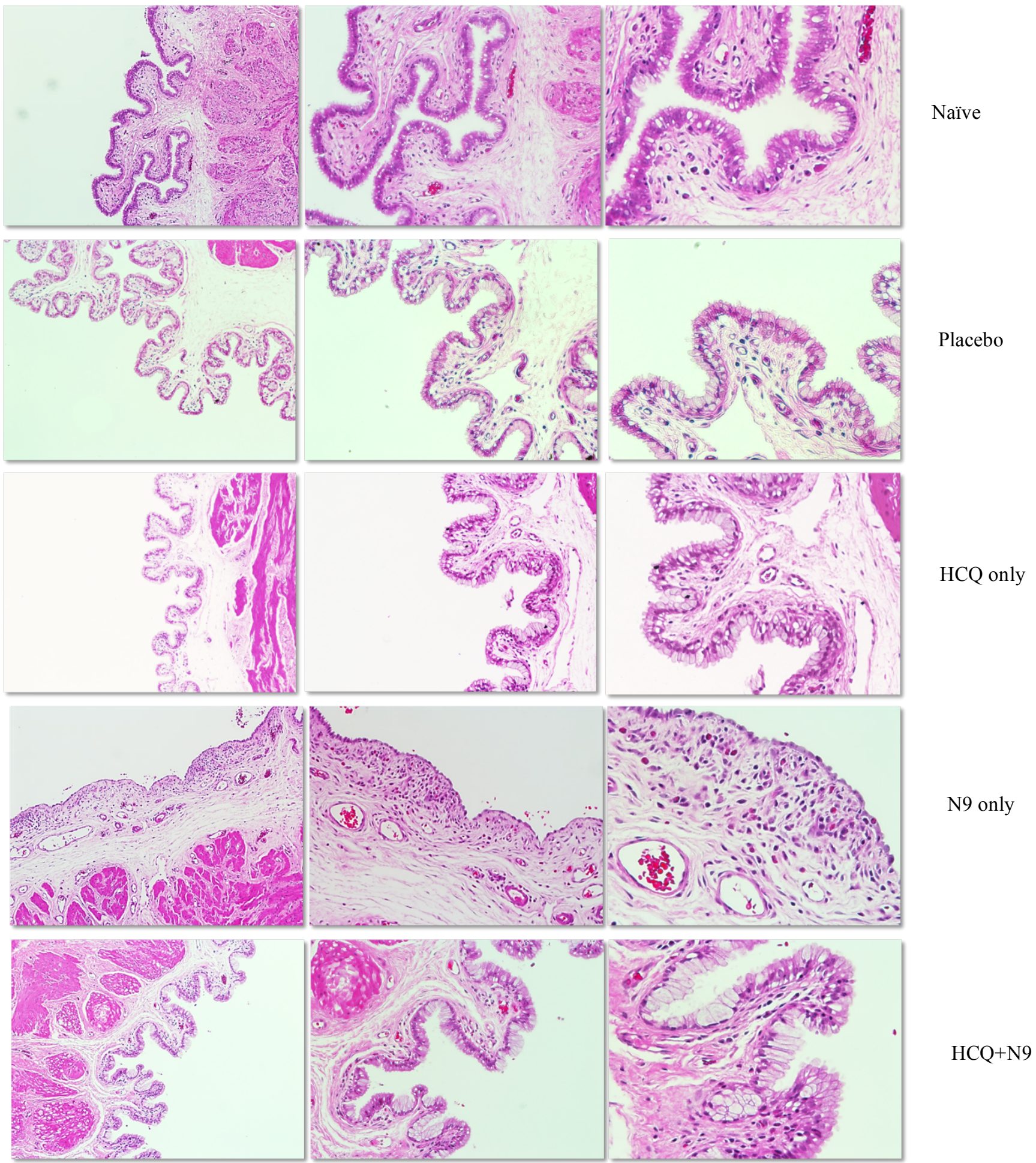

Fig. S9. Representative H\&E staining of the PC sections of rabbits collected on day 6 from naïve group, placebo group, HCQ only group, N9-challenged group, and HCQ implant group with N9 challenge. Images were acquired at $100 \mathrm{X}, 200 \mathrm{X}$, and $400 \mathrm{X}$ magnifications. 
Supplementary Table S1. The extraction efficiency of HCQ from different biological matrices and samples. CVL, cervicovaginal lavage; HCQ, hydroxychloroquine; CQ, chloroquine; EE\%, extraction efficiency expressed in percentage, mean $\pm \mathrm{SD}, \mathrm{N}=3$.

\begin{tabular}{|l|c|c|}
\hline Matrix or sample & Spiked HCQ Conc. $(\boldsymbol{\mu g} / \mathbf{m L})$ & HCQ EE\% \\
\hline Vaginal tissues & $0.3125,1.25$, and 5 & $92.8 \pm 3.6$ \\
\hline Blood & $0.15625,0.625$, and 2.5 & $94.9 \pm 4.3$ \\
\hline CVL samples & 1,5, and 20 & $100.1 \pm 7.7$ \\
\hline
\end{tabular}


a
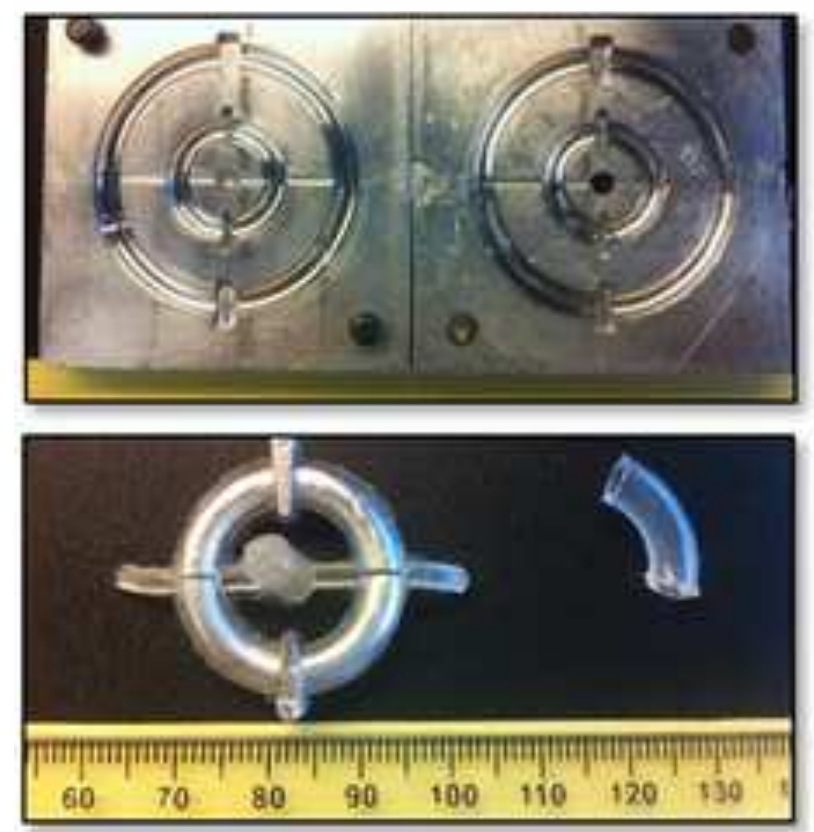

b

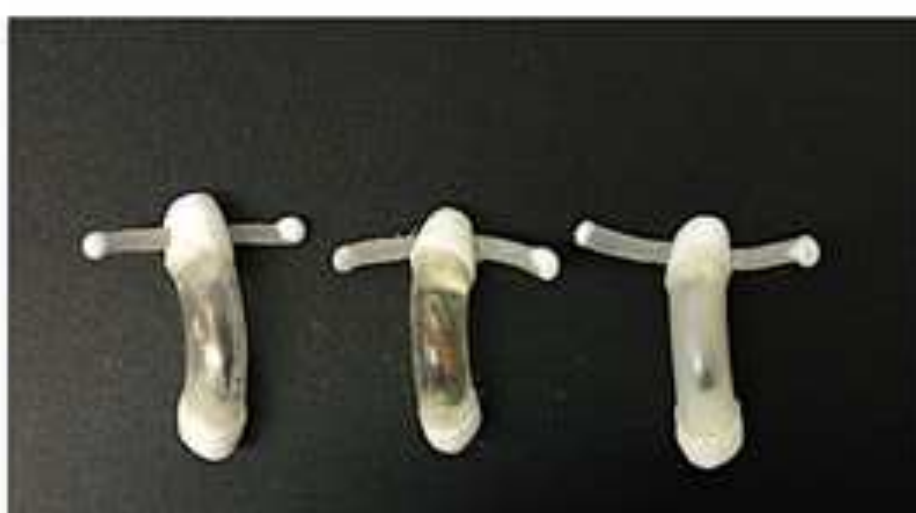

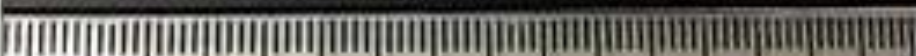

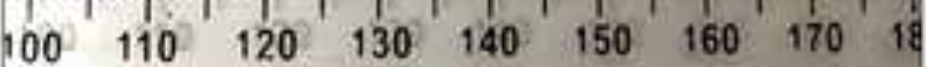

C

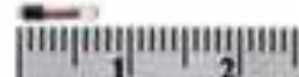

- rsn $\oplus$

d

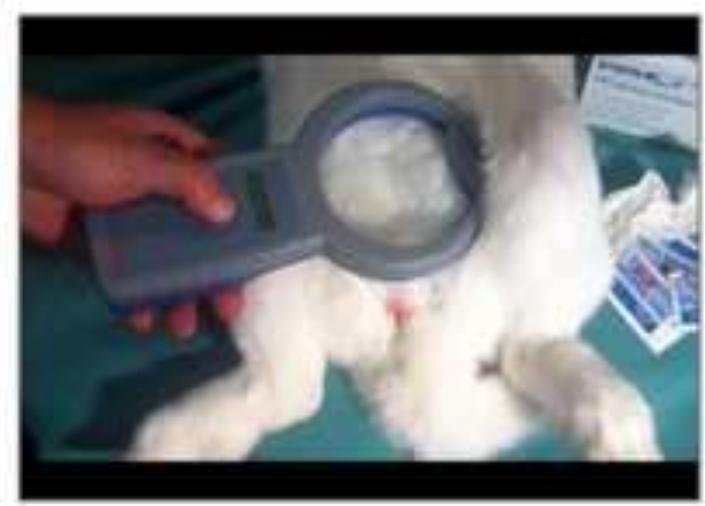


Click here to download high resolution image

a

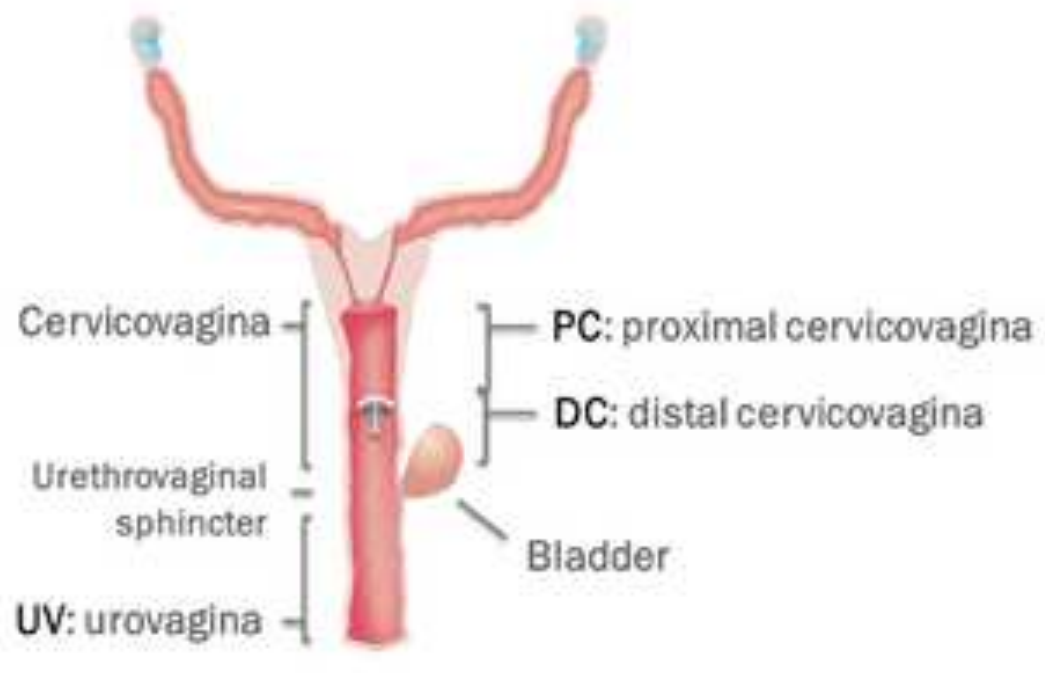

b

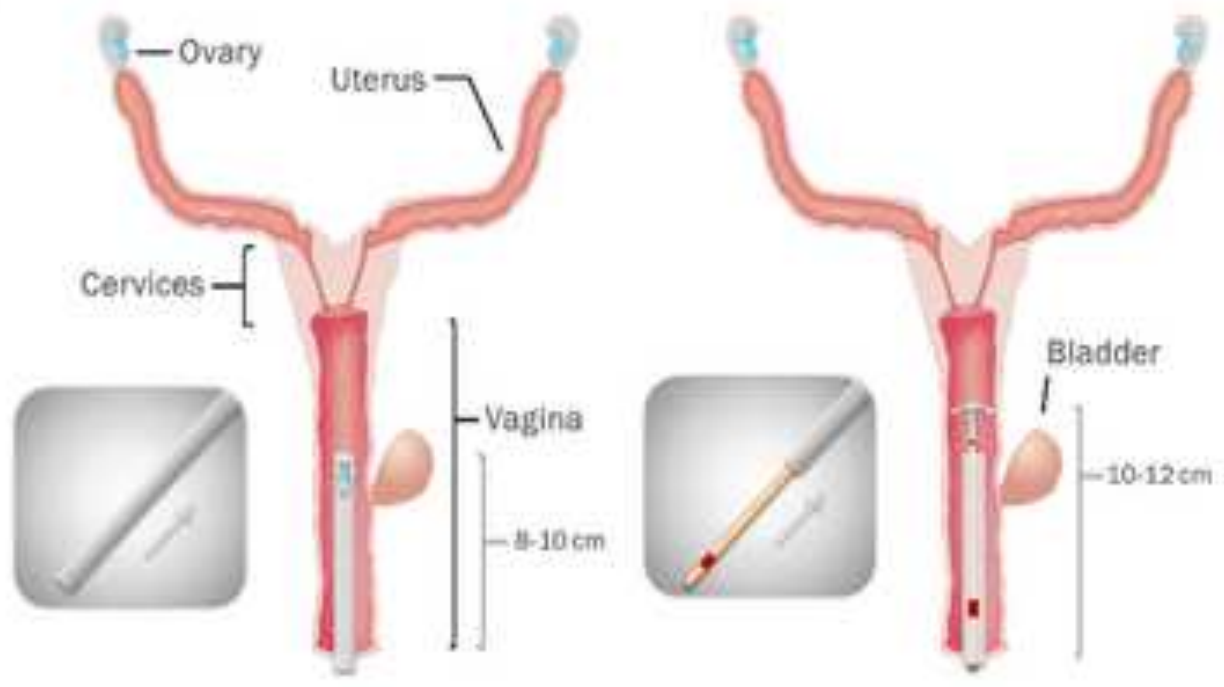

C

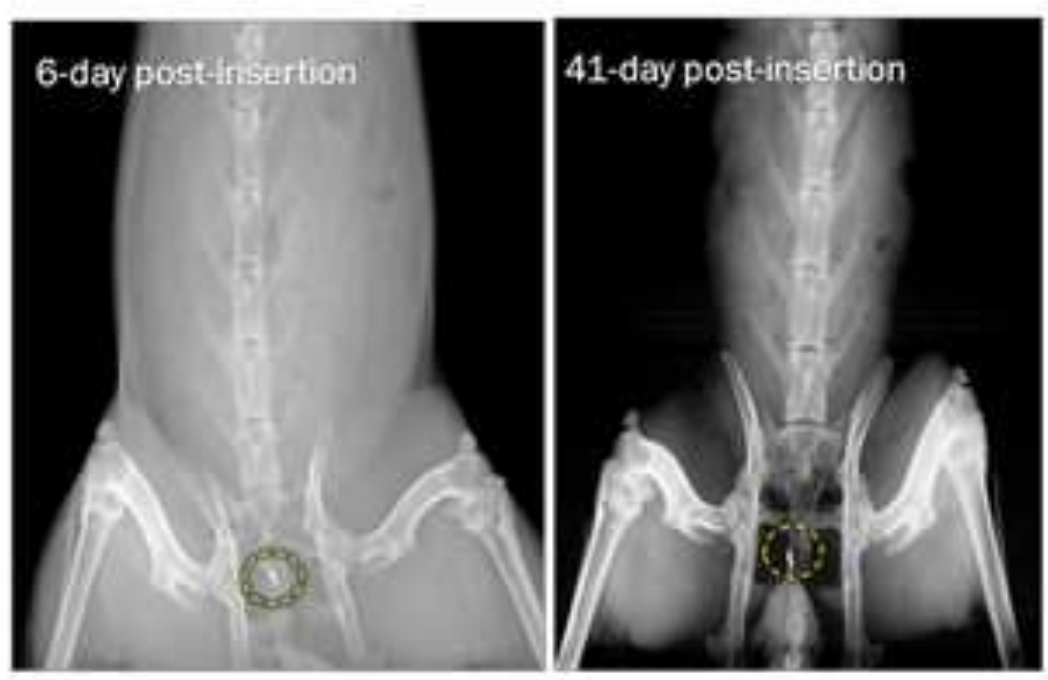


a

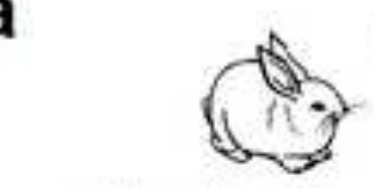

5-8 months old

New Zealand White

Rabbits

b

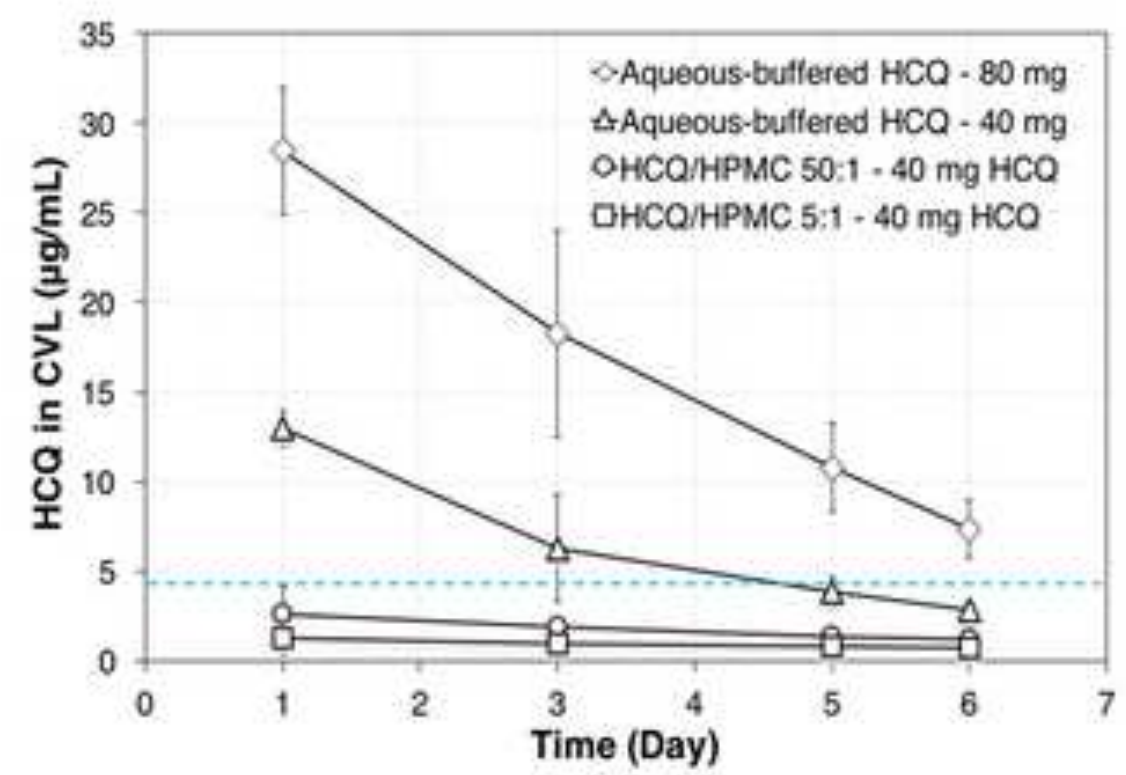

C

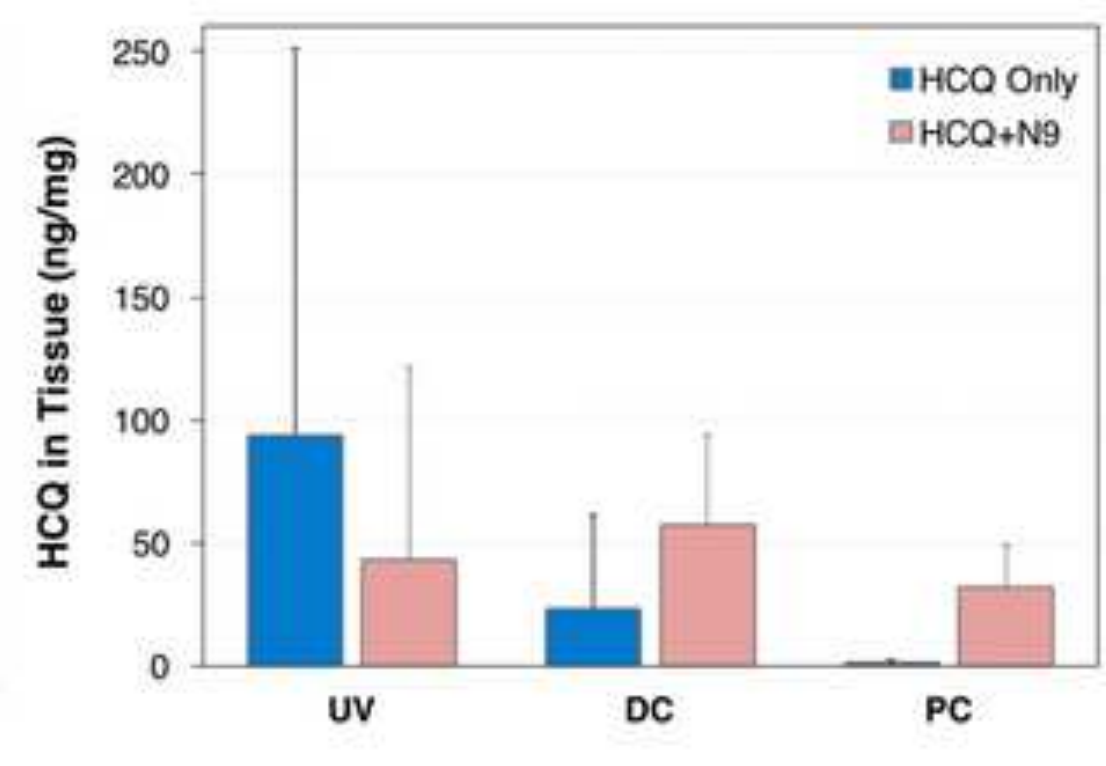

d

\begin{tabular}{|c|c|c|c|}
\hline Formulation & $\begin{array}{c}\text { Total drug } \\
\text { incorporated } \\
(\mathrm{mg})\end{array}$ & $\begin{array}{c}\text { HCQ delivery } \\
\text { rate } \\
(\mu \mathrm{g} / \mathrm{mL} / \text { day })\end{array}$ & $\begin{array}{c}\text { Duration of } \\
\text { therapeutic effect } \\
(>4.34 \mu \mathrm{g} / \mathrm{mL})\end{array}$ \\
\hline Aqueous-buffered & 80 & $16.19 \pm 3.34$ & 6 days \\
\hline Aqueous-buffered & 40 & $6.49 \pm 1.30$ & 3 days \\
\hline HCQ/HPMC 50:1 & 40 & $1.76 \pm 0.55$ & $\mathrm{n} / \mathrm{a}$ \\
HCQ/HPMC 5:1 & 40 & $0.96 \pm 0.32$ & $\mathrm{n} / \mathrm{a}$ \\
\hline
\end{tabular}

N9 Sacrifice

challenge \& tissue collection

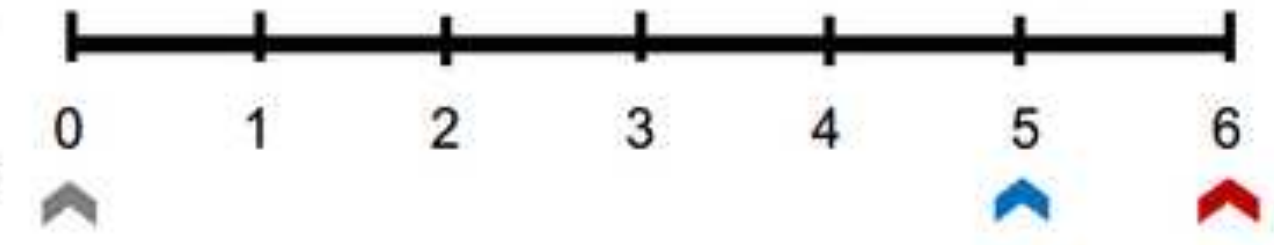




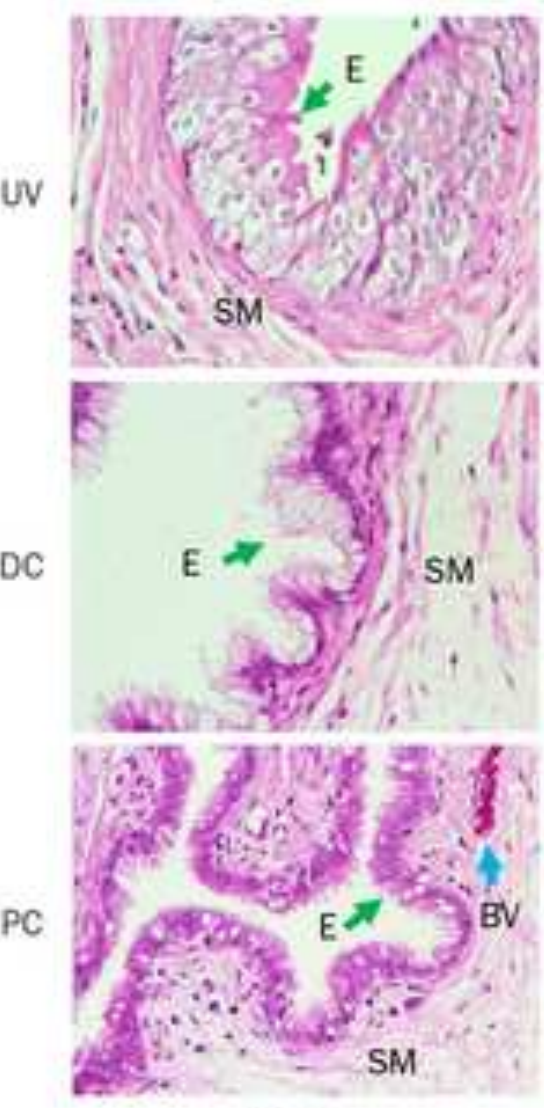

Naive
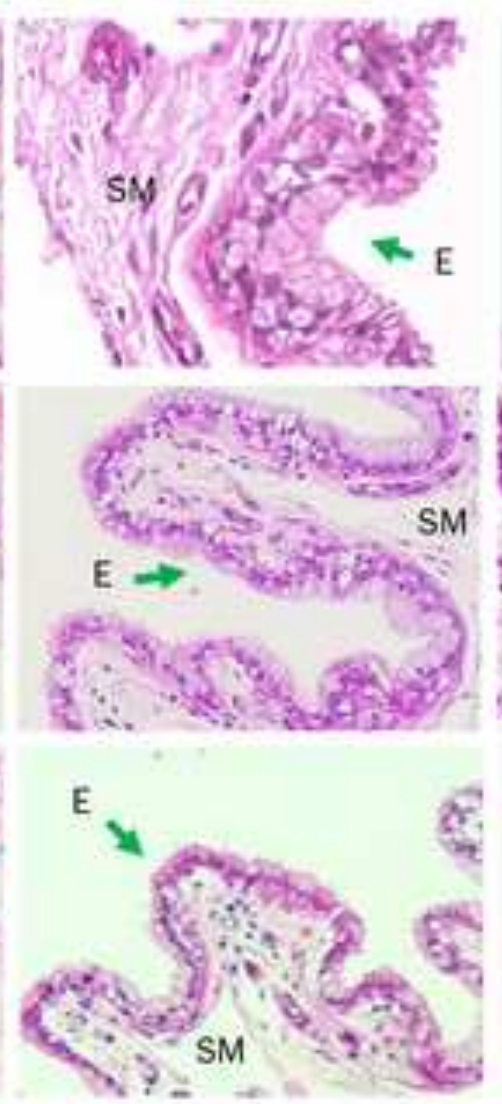

Placebo
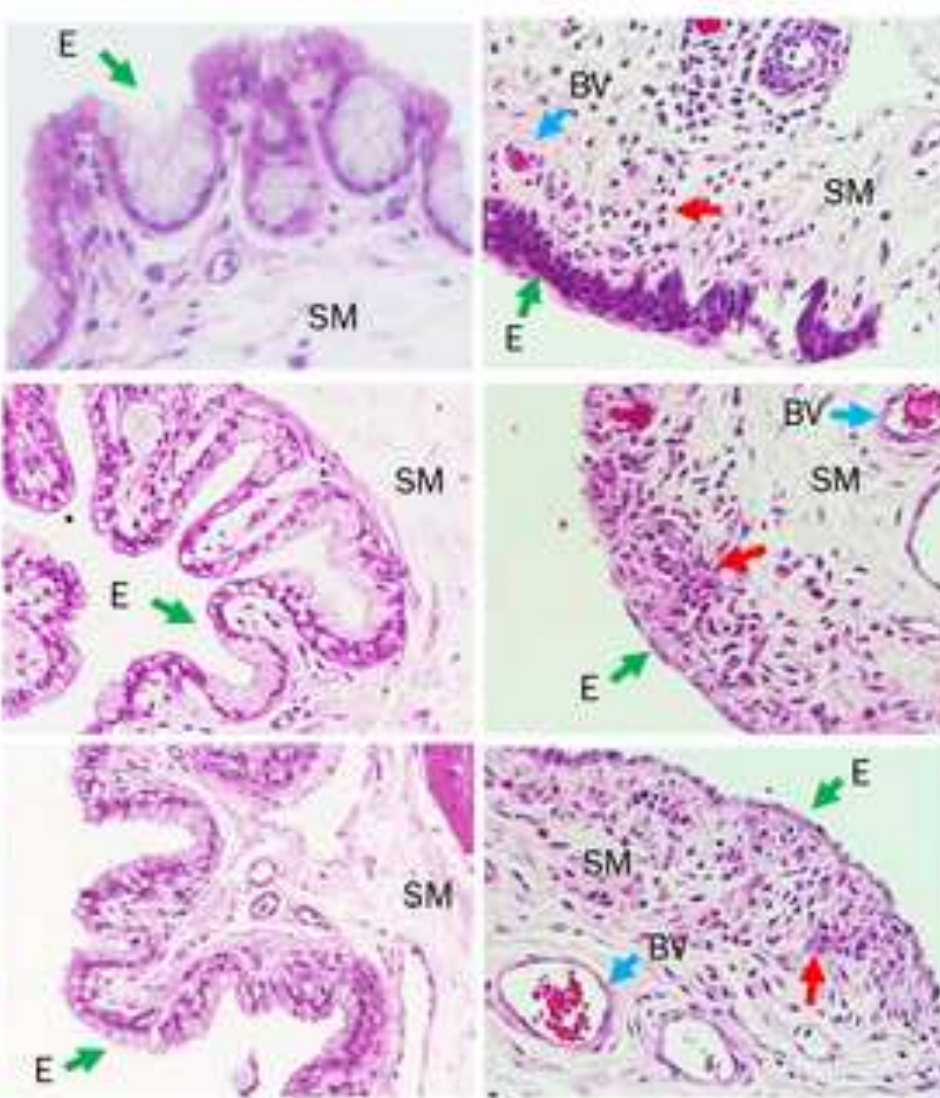

HCQ Only
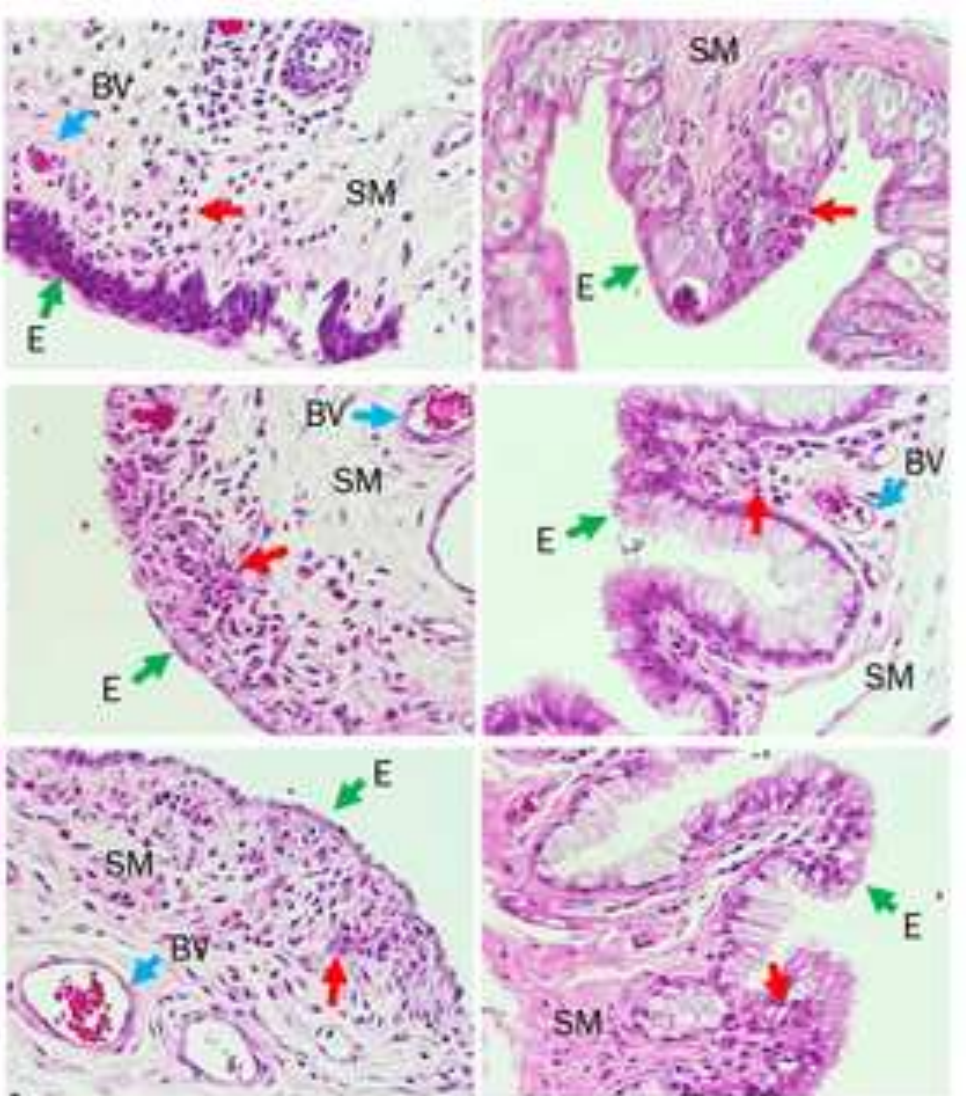

N9 Only

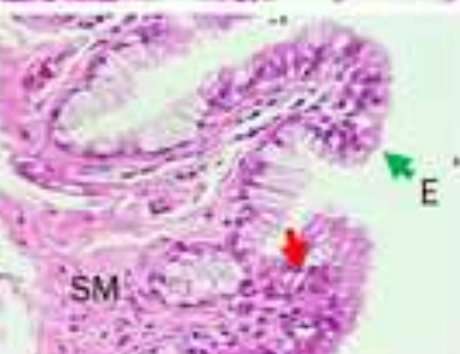

$\mathrm{N} 9+\mathrm{HCQ}$ 
a
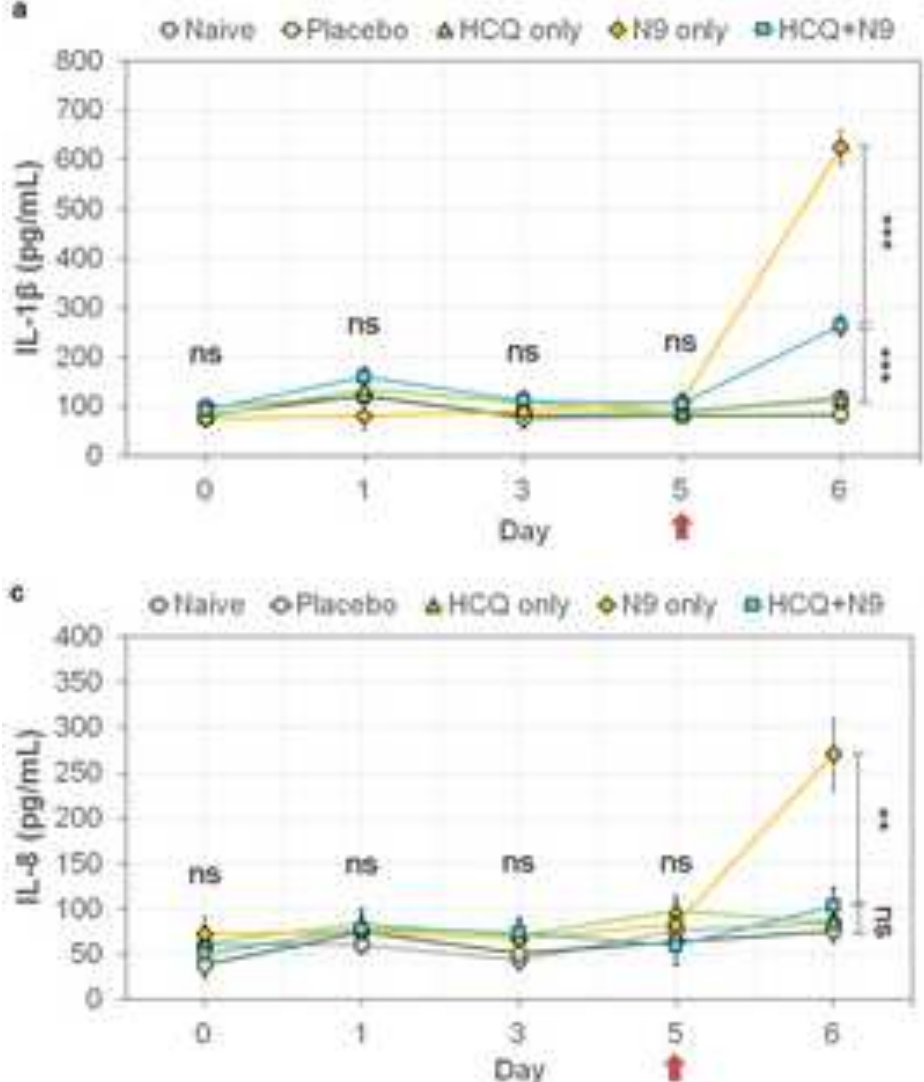

e

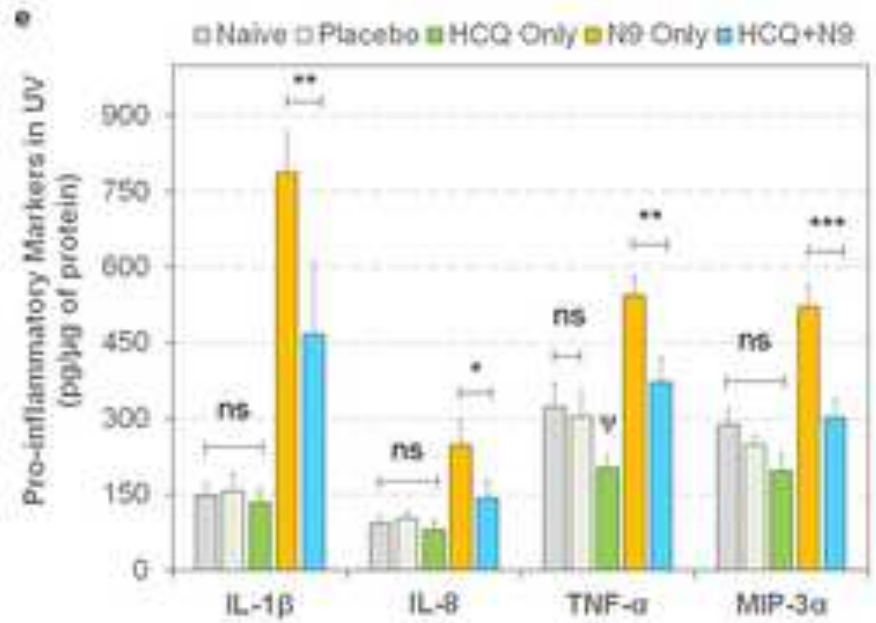

9
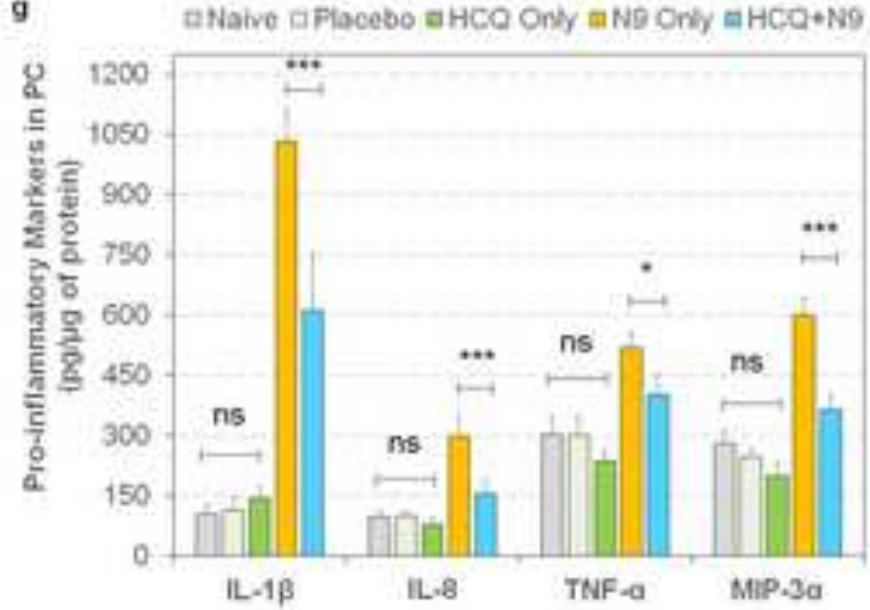
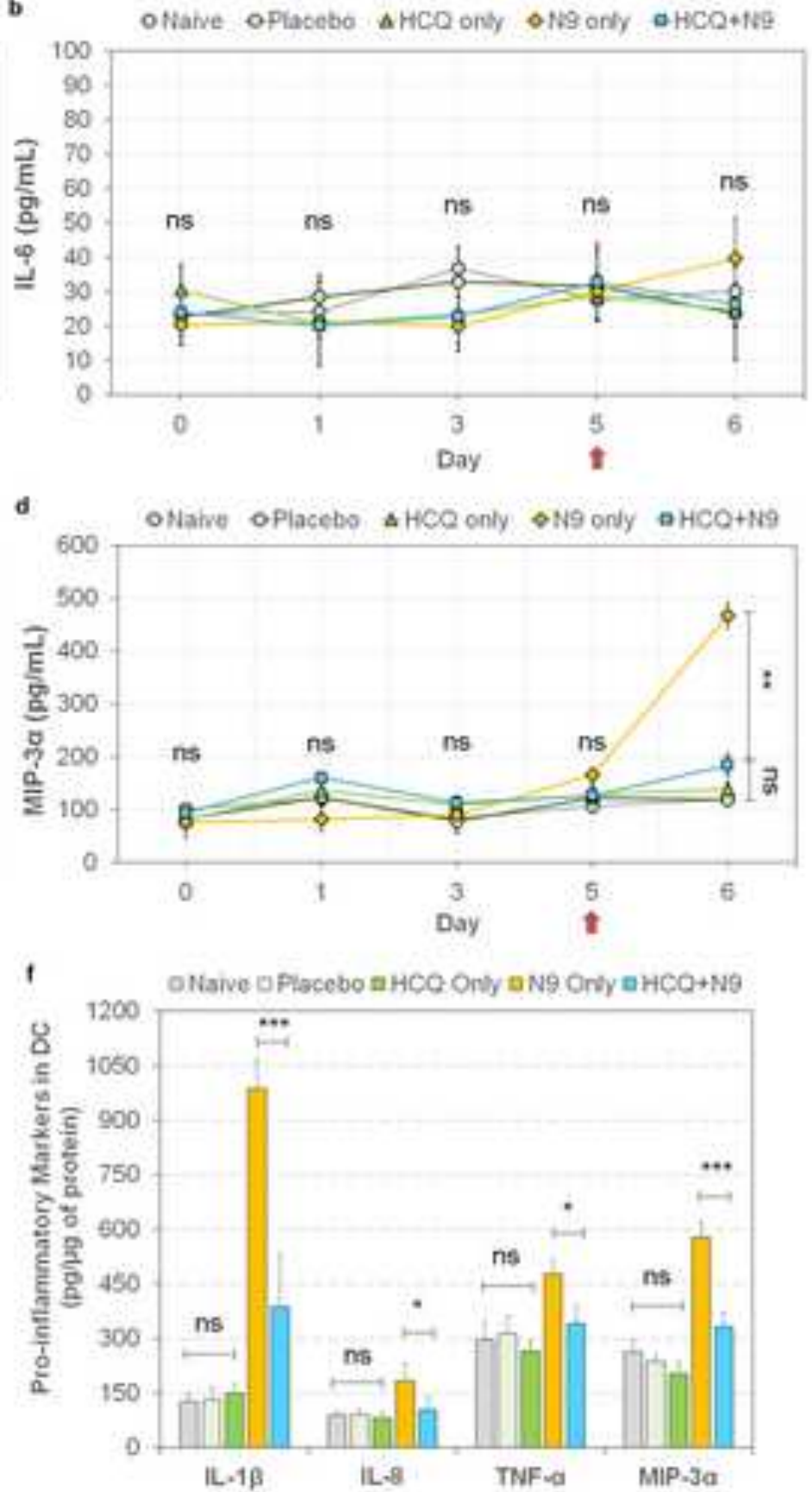
Click here to download high resolution image

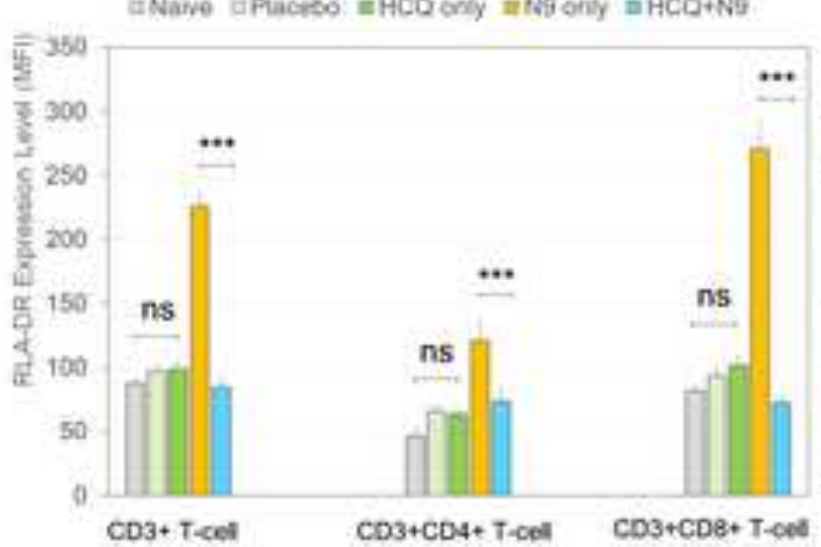

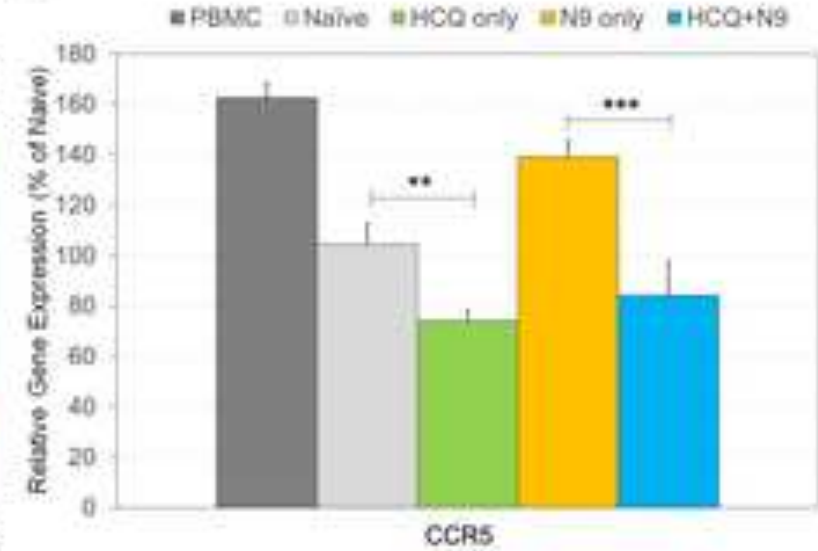

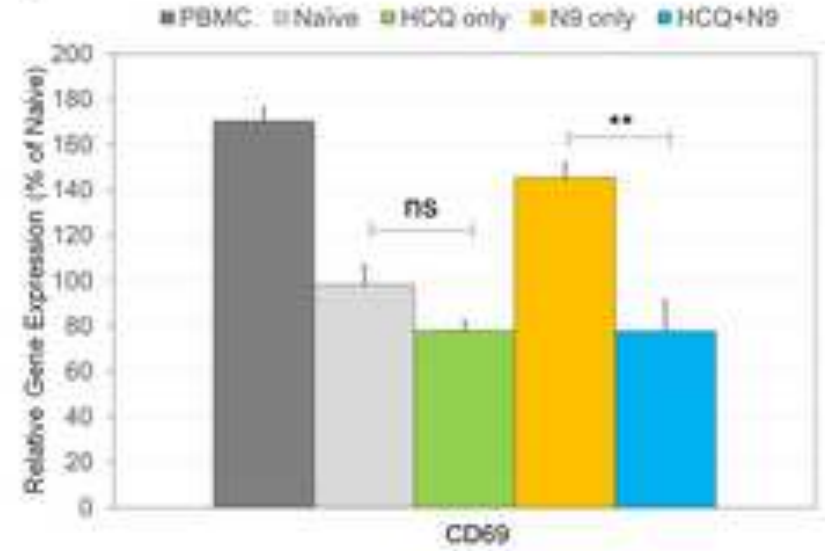


Supplementary Material

Click here to download Supplementary Material: (2018-01-17) Supplementary Material.docx

\begin{abstract}
Che here
\end{abstract} .

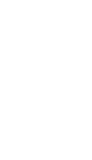

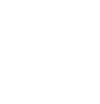

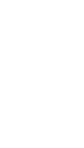

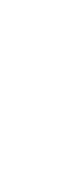

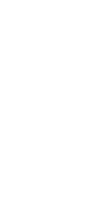
(

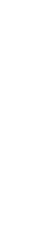
. . (1)

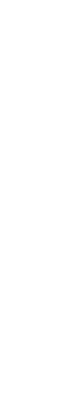
.

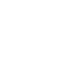

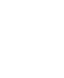
. . .

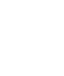
. 